\title{
THE IMPACT OF ALTERNATIVE NUCLEAR MORATORIUM LEGISLATION ON THE U.S. ECONOMY
}

\author{
DAVId J. Behling, JR.
}

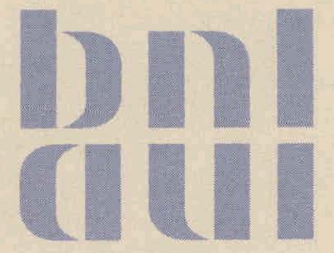

December 1976

ECONOMIC ANALYSIS DIVISION
NATIONAL CENTER FOR ANALYSIS OF ENERGY SYSTEMS

BROOKHAVEN NATIONAL LABORATORY ASSOCIATED UNIVERSITIES, INC. UNDER CONTRACT NO. EY-76-C-02-0016 WITH THE UNITED STATES ENERGY RESEARCH AND DEVFLOPMENT ADMINISTRATION 


\section{DISCLAIMER}

This report was prepared as an account of work sponsored by an agency of the United States Government. Neither the United States Government nor any agency Thereof, nor any of their employees, makes any warranty, express or implied, or assumes any legal liability or responsibility for the accuracy, completeness, or usefulness of any information, apparatus, product, or process disclosed, or represents that its use would not infringe privately owned rights. Reference herein to any specific commercial product, process, or service by trade name, trademark, manufacturer, or otherwise does not necessarily constitute or imply its endorsement, recommendation, or favoring by the United States Government or any agency thereof. The views and opinions of authors expressed herein do not necessarily state or reflect those of the United States Government or any agency thereof. 


\section{DISCLAIMER}

Portions of this document may be illegible in electronic image products. Images are produced from the best available original document. 


\section{THE IMPACT OF ALTERNATIVE NUCLEAR MORATORIUM LEGISLATION ON THE U.S. ECONOMY}

DAVId J. Behing, JR.

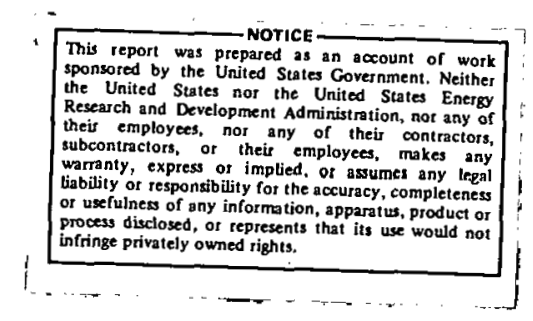

December 1976

THIS WORK WAS SUPPORTED BY THE

UNITED STATES ENERGY RESEARCH AND DEVELOPMENT ADMINISTRATION, ASSISTANT ADMINISTRATOR FOR INTERNATIONAL AFFAIRS AND DIVISION OF INTERNATIONAL SECURITY AFFAIRS

ECONOMIC ANALYSIS DIVISION

NATIONAL CENTER FOR ANALYSIS OF ENERGY SYSTEMS

BROOKHAVEN NATIONAL LABORATORYH UPTON, NEW YORK 11973 


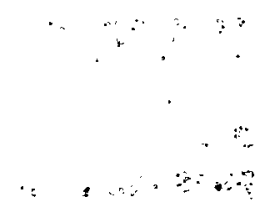

NOT I C E

This report was prepared as an account of work sponsored by the United States Government. Neither the United States nor the United States Energy Research and nevelopment Administration, îu ally of theis empluyees, nor anyy ont theır contractors, subcontractors, or their employees, makes any warranty, express or implied, or assumes any legal liability or responsibility for the accuracy, completeness or usefulness of any Information, apparatus, product or process disclosed, or represents that its use would not infringe. privately oumed righto.

Printed in the United States of America Available from

Natiunal Technical Information Service U.S. Department of Commerce 5285 Port Royal Road Springfield, VA 22161

Price: Printed Copy $\$ 6.00$; Microfiche $\$ 3.00$

February 1977 730 copies 


\section{Preface}

The initial purpose of this study was to be a demonstration of the analytical capabilities of the Brookhaven combined input-output linear programming model. Until recently, most general equilibrium models (both input-output and econometric) have been structured in such a fashion that they can only be used to estimate detailed energy "requirements" arising from expected trends in such demand parameters as population, aggregate productivity, and consumer preferences. By incorporating structural equations relating alternative energy supply activities to detailed economic activities, the framework of the Brookhaven combined model permits the reverse estimation of the level and structure of general economic activity which can be supported by given energy cost and availability conditions. The subject matter of this study was chosen primarily to illustrate this reverse linkage between detailed energy supply conditions and resulting levels of general economic activity.

As the study progressed, however, so did the probability of passage of some form of nuclear moratorium legislation. As a result, considerable attention has been devoted toward documenting the sources and methods used to estimate exogenous model parameters. In cases where there is considerable disagreement, particulaily with respcct to enexgl sestor variabies, solutions obtained from the combined model are compared with solutions obtained by the Federal Energy Administration using the Project Independence Evaluation System (PIES) model.

The study focuses primarily on the potential economic impacts which would result from nuclear moratoria legislation. Economic impacts estimated include those on industrial production and employment levels, as well as on aggregate 
consumption, investment and employment. While mention is made of other impacts, such as decreased nuclear radiation levels, increased coal-related environmental emissions and increased dependence on OPEC, no attempt is made to put dollar values on these other less strictly economic impacts. Thus the study yields only part of all the information relevant for assessment of nuclear moratoria legislation. In terms of the economic variables assessed, the primary focus is on the likely position of these variables in 1985 under a wide variety of energy supply and demand conditions which might occur over the 1975 to 1985 period.

The study itself has gone through several drafts. The author is indebted to Bill Marcuse and Phil Palmedo for their comments on earlier drafts, to Ken Hoffman, Ellen Cherniavsky and Morris Beller for their efforts in developing the linear programming model and estimating values of its various parameters, and to Ray Tessmer and Clark Bullard (of the Center of Advanced Computation of the University of Illinois) for their help in developing and estimating various parameters in the input-output model.

Special thanks go to Lee Abramson of the Energy Research and Developmont Administration for his patience as the study fell, further behind rinhoduled comm pletion dates, to Jane Nathan for typing several earlier drafts, to Yako Sanborn and Joan Lukachinski for their computer programming assistance and to Gerry Dennehey for his editorial assistance. Of course the views presented in this study are solely those of the author and should not be taken to be those of either Brookhaven or the Enerqy Research and Development Adminictration. 
Page No.

Chapter

I.

Introduction and Summary

Description of study . . . . . . . . . . . . . I

Nuclear Reduction Policies Considered . . . . . . 2

Energy Response Mechanisms Considered . . . . . . . 3

1985 Base Case Energy and Economic Projections . . . 5

Model Results - Changes from 1985 Base Case

Projections . . . . . . . . . . . . . 8

Analysis of Model Results . . . . . . . . . 15

Implications of Results for Public Policy . . . . . . 22

Chapter

II. Estimation of the Relationship Between Electricity, Energy and the Economy

Introduction . . . . . . . . . . . . . .

Importance of Assumptions Concerning Sulstitution

Mechanisms ................ 25

Substitution Mechanisms Employed in Other Models . . . 28

Substitution Mechanisms Employed in this Study . . . 29

Chapter

III.

Description of Combined Input-Output Linear Programming

Model ........................

Chapter

IV. Estimation of 1985 Base Case Model Parameters

Intruduclion . . . . . . . . . . . . . . 39

Final Demanas and GNR, Net of Encrgy . . . . . . . 40

Energy Product Final Demands . . . . . . . . . 45

Energy Supply Final Demands . . . . . . . . . 47 
Table of Contents (Cont.)

Page No.

Interindustry Energy Product Coefficients . . . . .

Interindustry Coefficients, Excluding Energy . . . .

Linear Programming Model Parameters . . . . . . .

Chapter

$\mathrm{v}$.

Base Case 1985 Energy and Economic Projections

Energy Supplies and Conversion Capacities . ......

Energy Demands . . . . . . . . . . . . . .

Non-Energy Sector Gross Outputs . . . . . . . .

Chapter

VI.

Estimation of the Impact of Possible Nuclear Moratorium Legislation of the 1985 Availability of Nuclear Electric Capacity

Introduction . . . . . . . . . . . . .

Estimation of the 1985 Base Case Amount of Nuclear

Eleclıic Capacity . . . . . . . . . . . .

Estimation of Alternative 1985 Amounts of Nuri.ear.

Electric Capacity . . . . . . . . . . . "

Chapter

VII.

Specification of Possible Responses to Decreases in the 1985 Base Case Amount of Nuclear Electric Capacity

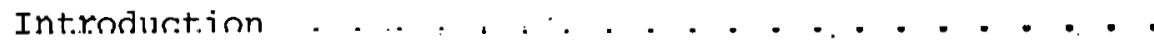

Response Cases Considered . . . . . . . . . .

Chapter

VIII. Presentation and Analysis of Model Results

Coal Response Case . . . . . . . . . . . . .

Imported Oil Response Case . . . . . . . . .

Conservation Response Case .............. 
Table of Contents (Cont.)

Page No.

Comparison and Analysis of 1976 to 1985 Response

Cases . . . . . . . . . . . . . . .

Analysis of 1985 Curtailment Case . . . . . . .

References

Implications of Results for Public Policy . . . . . .

Appendix A I-O Model Sectoral Alignment and 1985. Non-Energy

Final Demand Estimates . . . . . . . . . 97

Appendix B Cost Tables for Linear Programming Model . . . . . . 101 
Page No.

I.1 1974 and Alternative 1985 Base Case Energy

Projections . . . . . . . . . . . . . . . .

I.2 1974 and 1985 Base Case Economic Projections . . . . . .

I.3 Selected Energy and Economic Effects of the Coal Response Case to Alternative Nuclear Policies .........

I.4 Coal and Coal Electric Capacity Requirements for Coal Rooponse Case, 1994-1ybb . . . . . . . . . . . .

I.5 Selected Energy and Economic Effects of the Imported Oil Response Case to Alternative Nuclear Policies . . . . .

I.6 Selected Energy and Economic Effects of the Conservation Response Case to Alternative Nuclear Polisioc . . . . .

III.1 Classification of Variables Contained in Combined IO-IP Model . . . . . . . . . . . . . . .

IV.I Alternative GNP Projections to 1985 . . . . . . . . .

IV.2 Final Demands for Energy Products, 1967 and 1985. . . .

IV. 3 Final Demands for Energy Supplies, 1967 and 1985 . . . .

V.1 1985 Rase Gase Amounta of Ellelyy Supplles and Conversion Caparities ....................

V.2 Domestic Energy Production, 1967 to 1985 .........

V.3 Uomestic Energy Consumption, 1967 to 1985 . . . . . . .

V.4 Gross Domestic Output, by Non-Energy Sector, 1967 to 1985 . . . . . . . . . . . . . .

VI.1 1985 LWR and HTGR Nuclear Electric Capacity Amounts, by Trpe of Nurlear Pulicy . . . . . . . . . . .

VIII.1 Coal Response Case Model Results - Energy Sector Variables . . . . . . . . . . . . . . .

VIII.2 Coal Response Case Model Results - GNP Variables . . . • 
Iist of Tables (Cont.)

Page No.

VIII.3 Imported Oil Response Case Model Results - Energy Sector Variables . . . . . . . . . . . . . . . . 83

VIII.4 Imported Oil Response Case Model Results - GNP Variables . . . . . . . . . . . . . . . . . .

VIII.5 Conservation Response Case Model Results . . . . . . . 
I.1 Percentage Reduction in: 1985 GNP for Alternative Nuclear Policies and Supply Responses . . . . . .... . ....

I.2 Curtailment Case: Percentage Reduction in 1985. GNP, , Consumption and. Investment Resulting from Reductions in 1985 Nuclear Capacity Availability . . . . . . . . .

II.1 Energy, Employment and GNP Relationships, Generalized ...

II.2 Energy, Employment and GNP Relationships, Limited ex post... . . . . . . . . . . . . . . . . .

III.1 Two Level Iterative Input-Output Linear Programing Model . . . . . . . . . . . . . . . .

IV.1 Five Year Average Annual Growth Rates of GNP, 1.950=.1955 to $1980=1985$. . . . . . . . . . . . . . .

IV.2 1967 to 1985 Percentage Change in 19 Aggregate Final Demands.....................

VIII.1 Percent Change in 1985 Base Case Amounts of Non-Energy. Outputs with Coal Response to Nuclear Policies . . . .

VIII.2 Percent Change in 1985 Base Case Amounts of Energy Product Consumption with Coal Resnonse to Nuclear Policies . .

VIIt.3 Change in 1985 Base Case Emplnyment in selected Industries with Coal Response to Total Ban Nuclear Policy . . . .

VIII.4 Percent Change in 1985 Base Case Amounts of Non-Energy Outputs with Imported Oil Response to Nuclear Policies . . . . . . . . . . . . . . . . .

VIII.5 Change in 1985 Base Case Empluyment in Selected Industries with Imported Oil Response to Total Ban Nuclear Policy

VIIT̄. Fercentage Reduction in 1985 GNP for Alternative Nuclear Policies and Supply Responses . . . . . . . . . . .

VIIT. $7^{\circ}$ Curtailment Case: Percent Reduction in 1985 GNP, Consumption and Tnvestment Resultiny from Keductions in 1985 Nuclear Electric Capacity . . . . . . . . . 


\section{$\underline{\text { Abstract }}$}

This study analyzes the potential economic impact of policies which would contain or halt the introduction of additional nuclear electricity plants as well as the operation of currently existing nuclear plants. First a Base Case set of energy and economic projections for 1985 is estimated under the assumption that by 1985174.2 gigawatts of nuclear electric capacity will be available to the economy. Then the impacts of four potential nuclear policies on these Base Case economic and energy projections are estimated. Two of the four nuclear policies would decrease the expected 1975 to 1985 growth rate of nuclear capacity expansion, one would keep nuclear capacity in 1985 at the prosent 36.1 gigawatt amount, and one would phase out all nuclear capacity by 1985. The following general conclusions are reached. As long as relative primary fuel prices do not change significantly from current patterns, coal-based electricity production will be the least-cost supply alternative to nuclear electricity production in most regions of the country over the 1975 to 1985 period. Should all expected 1976 to 1985 nuclear electric capacity expansion be replaced by additional coal electricity capacity expansion, the 1985 GNP would decline approximately .02\%. Replacement of presently existing nuclear capacity as well with additional coal electricity capacity would involve a further $.02 \%$ decline in the $1985 \mathrm{GNP}$. Much of the GNP reduction would be concentrated in those regions of the country which are not readily accessible to low sulfur coal deposits, such as New England.

Large increases in coal production and in coal electricity plant expansion rates would be requiren to keep GNP reductions to these small amounts. Barring such greatly accelerated coal activity, some additional oil steam electric plant capacity expansion would also be required to compensate for large. 
nuclear reductions. Assuming a $\$ 9$ per barrel price for imported oil in 1985 (in constant 1974 ), reliance on additional oil steam electric capacity as a replacement for nuclear capacity would involve costs, in the form of 1985 GNP foregone, roughly double those for coal. Reliance on imported oil as a replacement for nuclear capacity would also increase costs arising from possible oil embargoes. Higher imported oil prices would lead to correspondingly greater costs.

Under either a coal or oil based elcctricity expansion response to nuclear cut-backs, aggrogate electrinity prnducliun fin 1985 would decline slightly. As the production costs and price of electricity increased, increased amounts of oị and gas would be substituted for electricity in providing space heat, water heat, and process heat. Should some of the resuurces originally committed to expanding nuclear capacity be realloratad toward providing more energy efficient end use equipment, 1985 electricity production requirements would decline further.

In sunulyy, as long as some combination of coal, imported oil, and conservation response to nuclear wutbacks ran bc implemented in a 1976 to 1985 time frane, the nveralil coviumle iupact of these alternatives would be to decrease the 1985 GNP by only small amounts. On the other hand, the costs in 1985 of failing to provide for supply and/or conservation alternatives to nuclear electricity over the 1975 to 1985 period would be large and would increase more than proportionately to the amount of uncompensated nuclear shortfall. The 1985 GNP worlit decrease up to $30 \%$ with an uncompensated 100\% shortfall in the amount of expected nuclear capacity, and up to $5 \%$ with a $40 \%$ uncompensated shortfall. The costs of nuclear replacements and/or shortfalls would also extend beyond 1985. The extent of these future costs would depend 
primarily upon the future prices of coal, oil, and fabricated uranium, all of which are highly uncertain at the present time.

The public policy implications of these results are clear. If society wishes to delay or completely forego nuclear electricity production, only slightly more expensive alternatives are available. Failure to provide a favorable environment for these alternatives, however, will increase the employment and real income costs of nuclear moratorium legislation to intolerable amounts. Since considerable lead times are required for provision of alternatives, society cannot afford to both hinder the development of nuclear power and to procrastinate as to which of the alternatives to nuclear power is most desirable. 


\section{Chapter I. Introduction and Summary}

\section{Description of Study}

This study analyzes the potential economic impact of policies which would contain or halt the introduction of additional nuclear electricty plants as well as the operation of currently existing nuclear plants. First a Base Case set of energy and economic projections for 1985 are estimated under the assumption that by 1985174.2 gigawatts of nuclear electric capacity will be available to the economy. Then the impacts of four potential nuclear policies on these Base Case economic and energy projections are estimated. Two of the four nuclear policies would decrease the expected 1976 to 1985 growth rate of nuclear capacity expansion, one would keep nuclear capacity in 1985 at the present 36.1 gigawatt amount, and one would phase out all nuclear capacity by 1985 . The following methodology is used to estimate the 1985 economic impacts of each of the four nuclear policies. First, using an input-output model of the economy (IO) linked to a cost minimizing linear programing model of the energy sector (LP), a "Base Case" 1985 reference projection of outputs, employment, and final demand is estimated for 20 different energy sectors and 90 different non-energy sectors. As part of this Base Case projection, it is assumed that there will be 174.2 gigawatts of nuclear electric generating capacity available for use in 1985, an amount slightly less than that recently projected for 1985 by the Energy Research and Development Administration (ERDA). Next, four alternative 1985 amounts of nuclear electric capacity availability are estimated on the basis of four potcntial nuclear renuction policies. For each of these four smaller sized 1985 nuclear capacity amounts, several possible coal, oil, and conservation responses are considered, and the same IO-LP model 
is solved for GNP, output and employment values. The solution values of GNP, output, and employment obtained for each nuclear cutback and each response mechanism are then compared to the Base Case solution values so as to obtain the impact of the nuclear cutback and the response mechanism being analyzed. For all cases considered, it is assumed that capital costs for different types of electric capacities will be as follows in 1985 (in constant 1974 \$):

- Lights-water reactors; $\$ 520 / \mathrm{kW}(\mathrm{e})$

- Coal-fired stean plants; $\$ 425 / \mathrm{kW}(e)$

- Oil-fired steam plants; $\$ 280 / \mathrm{kW}(e)$

and that fuel costs will be as follows (in constant (1974\$):

- Fabricated uranium; $\$ .30 / 10^{6} \mathrm{BTU}(t)$

- Coal; $\$ 15.45 /$ ton at the minemouth

- Residual fuel oil; $\$ 9.00 /$ barrel at the refinery

These fuel and capital costs were estimated by the Energy Technology Assessment Group (ETAG) of Brookhaven on the basis of current policy and economic trends extrapolated to 1985. Recently, in conjunction with other Brookhaven studies in progress, most of these cost estimates havc been increased. However little change has been made to relative cost differentials between different fuels and electric generating capacities. Nuclear Reduction Policies Considered

Four alternative policies affecting the future rate of growth of nuclear facilities to 1985 are considered. It is assumed that each of these policies would be enacted in the latter part of 1976, allowing a nine year adjustment period between the enactment of the policy and the state of the economy in late 1985. The policies considered are as follows: 
1) "Moratorium" - A two year moratorium is imposed in late 1976 on all nuclear electric plants planned or under.construction as of that time, while only nuclear plants operating as of January 1, 1977 are permitted to remain in operation. Further, it is assumed that this moratorium is followed by a delayed continuation of previously planned nuclear construction activities. Under this policy the estimated 1985 Base Case amount of nuclear electricity capacity would be reduced by $40 \%$ to 104.5 gigawatts.

2) "No New" - A permanent ban is placed on all construction not initiated by late 1976 so that the 1985 capacity would be limited to those plants presently operating or under construction as of late 1976. Under this policy the estimated 1985 Base Case amount of nuclear capacity would be reduced by $43.8 \%$ to 97.6 gigawatts.

3) "Old Only" - A permanent ban is placed on the operation of nuclear plants not completed by January 1, 1977. This policy would reduce the estimated 1985 Base Case amount of nuclear electric capacity by $79.2 \%$ to 36.1 gigawatts.

4) "Total Ban" - A ban is placed on the operation of all nuclear plants.

\section{Energy Response Mechanisms Considered}

Three alternative intermediate term supply and demand responses to the 1976 nuclear policies are considered. It is assumed that each response would start concurrenlly with the 1976 nuclear poligy heing considered, and that each would operate quickly enough so as to eliminate any potential excess demand for electricity. These intermediate response cases are as follows:

Intermediate Term Supply Response Case 1: "Coal" - In this case it is assumed that increases in coal production, at a constant cost of $\$ 15.45$ per ton (1974\$), and in coal steam electric capacity, at a constant cost of $\$ 125 /$ kW(e) (1974 \$), between 1976 and 1985 would be sufficient to compensate for 
decreases in the 1985 planned amount of nuclear capacity. GNP decreases in 1985 would be limited to the effects of the increased real costs of producing electricity with coal rather than with uranium. Decreases in electricity consumption would be limited to decreases resulting from substitution of direct fuels for electricity in meeting heating requirements. Intermediate Term Supply Response Case 2: "Imported Oil" - In this case it is assumed that increases in oil imports and oil steam electric capacity between 1976 and 1985 would be sufficient to compensate for decreases in the 1985 Base Case amount of nuclear capacity. In addition, it is assumed that fore eash additional dollar spent on oil imports, non-energy net exports would increase by 60 cents and capital flows by the remaining 40 cents. Personal consumption decreases result both from the increased real costs of producing electricity with imported oil rather than uranium and from balance of payments effects. Decreases in electricity consumption are limited to decreases resulting from substitution of direct fuels for electricity in meeting heating requirements. Intermediate Term Demand Response Case 3: "Conservation" - In contrast to the above two supply response cases, in thie aasc it is assuilied that the 1985 level and $\mathrm{mix}$ of non-nuclear fuel supply availabilitiee and electric generating capacity availabilities remain constant at Base Case values. Instead, the IO-LP model is used to solve for the degree to which the energy input efficiencies of end use devices would have to increase and/or the degree to which the demand for the services of end use devices would have to decrease in order to compensate for deçeases in the Base Cage amount of multudr clcctric capaiity.

Curtailment Response Case - In this case it is assumed that values of all non-nuclear energy supplies and electric generating capacities remain 
fixed at estimated 1985 Base Case amounts and that interindustry energy requirements per unit of output also remain fixed at 1985 Base Case amounts. Given these assumptions, any reduction in electricity output associated with cutbacks in nuclear capacity would lead to reductions in electricity sales to consumers with consequential losses of satisfaction and/or to reductions in electricity sales to producing sectors with resulting decreases in output and employment in the non-energy sectors.

1985 Base Case Energy and Economic Projections

The 1985 Base Case energy projections obtained from solution of the combined model are listed in column 2 of Table I.l. These projections were estimated under the assumption that the price of oil imports in 1985 would equal $\$ 9.00$ per barrel (in 1974\$). Recently the Federal Energy Administration (FEA) also estimated a set of 1985 reference energy forecasts under the assumption that the 1985 price of imported oil would equal $\$ 12.00 /$ barrel (in 1974\$) (1). The FEA forecasts are listed in column 3 of Table I.l. Relative to the projections obtained from the combined model, they include less oil imports, more domestic coal production and more coal-generated electricity production. Since the implications of results obtained from changes in model parameters are quite sensitive to the Base Case values against which they are compared, the analysis of model results for alternative nuclear policies and response cases are compared against both sets of 1985 energy Base Cases. For comparison with current conditions, historical 1974 estimates are listed in column 1.

The 1985 Base Case economic projection of GNP and its components are presented in Table I.2, along with historical 1974 data. In the Base Case, real GNP is estimated to grow 3.9\% per year between 1974 and 1985. Economic pro- 
1974 and Alternative 1985 Base Case Energy Projections Amounts and Average Annual Growth Rates

1974

(quads)

1985
BNL

(quads) (quads)

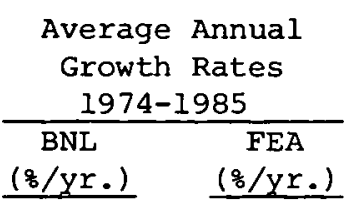

Consumption of

Primary Resource Inputs

\section{Coal}

Oil and Oil Shale

Natural Gas

Nuclear

Other

Total

\begin{abstract}
13.27
33.41

22.03

1.20

3.25
\end{abstract}

73.16
14.60
47.57
26.50
10.13
4.07

102.87
20.54
41.27
24.35
8.67
4.04

98.87
0.9
3. 3
1.7
21.4
2.1

4.1

I.y

0.9

19.7

2.0

3.1

2.8

Primary Resource Imports

Nil.
Natural Gas
$\quad$ Total

\begin{tabular}{rrrrr}
13.20 & 22.97 & 12.12 & 5.9 & $\ldots .0 .1$ \\
0.00 & 3.00 & 1.34 & 0 & $\infty$ \\
\hline 12.20 & 25.97 & 13.46 & 7.1 & 0.9
\end{tabular}

Electric Generating Capacities (in terms of annual quads of energy inputs processed)

rnal Steam
Oil Steam
Gas Stcam
Gas Turbine
LWR.
HTGR
Hydro
Geothermal

\begin{tabular}{rrrrr}
8.51 & 7.25 & 15.38 & -1.5 & 5.5 \\
3.18 & 2.73 & 1.40 & -1.4 & -7.2 \\
3.31 & 3.40 & 3.05 & 0.2 & -0.7 \\
0.50 & 0.67 & 1.30 & 2.7 & 9.1 \\
1.30 & 9.32 & 8.67 & 21.2 & 10.7 \\
0.00 & 0.21 & 0.00 & $\infty$ & 0.0 \\
3.25 & 3.38 & 3.38 & 0.4 & 0.4 \\
0.00 & 0.69 & 0.56 & $\infty$ & $\infty$ \\
\hline 19.99 & 28.25 & 33.74 & 3.2 & 4.9
\end{tabular}

Total

28.25

3.2

4.9

Sources: 1974 and 1985 FEA - 1976 National Energy Outlook, Federal Energy Administration, FEA-N-75/713, February 1976

1985 BNL - Model results 
Table I.2

1974 and 1985 Base Case Economic Projections Amounts and 1974-1985 Average Annual Growth Rates

1974

(billions

of 1967\$)

Personal Consumption

Expenditure

Gross Investment

Government spending on

Goods and Services

Net Exports

Total, Gross National Product
617.7

132.8

184.6

13.6

948.7
1985

(billions

of $1967 \$$ )
1974-1985 Average Annual Growth Rates ( $8 /$ yr.)

Sources: 1974-Survey of Current Business, U.S. Department of Comerce. Bureau of Economic Analysis, January 1976.

1985-Behling, D. J. and Dennehy, G. Estimation of Final Demands and Current Input-Output Coefficients to 1985, Brookhaven National Laboratory, Informal Report \#20369, August 1975. 
jections estimated for each alternative nuclear policy and each response case are compared to these 1985 GNP projections.

Model Results-Changes from 1985 Base Case Projections

Intermediate Supply Case 1: "Coal" - Selected energy and economic effects of expanding coal production and coal steam electric capacity and simultaneously contracting uranium production and additions to nuclear electric generating capacity are presented in Table I.3. For all policies except the Total Ban nuclear policy, the 1985 GNP would decline only slightly, as the national average cost of producing electricity via coal in 1985 is estimated to be only slightly greater than that for nuclear-based electricity generation. In the Total Ban nuclear policy, the 1985 GNP would be reduced by $.035 \%$ before allowance is made for the fact that presently existing nuclear capacity could not be readily converted to any alternative uses. When allowance is made for wasting the labor and capital resources incorporated in presently operating nuclear facilities, the GNP reduction increases an additional .10\% (equal to $\$ 1.44$ billion in constant $1967 \$$ ) to $.135 \%$ (equal to $\$ 1.95$ billion in constant $1967 \$$ ). While the aggregate reduction in GNP is small, for all nuolcar policies ex= cept the 'l'otal Ban case, a considerable change in the composition of economic activity would be required to achieve these results. Since the direct plus indirect capital requirements of producing coal and coal electric capacity are less than those for constructing and operating the complete nuclear fuel cycle, including nuclear plants, aggregate invectmont requiremeils fur the economy in 1985 decrease up to 8.1\% for the old only nuclear policy case, while the production of final consumer goods and services increases up to $1.7 \%$ in 1985 for the old only nuclear policy case, In the Total Ban policy case, the resource waste involved in foregoing the use of currently existing nuclear plants would 
Table I. 3

Selected Energy and Economic Effects of the

Coal Response Case to Alternative Nuclear Policies

(All Changes Relative to Estimated 1985 Base Case Amounts)

\section{Nuclear Policy}

Moratoriura

No New

old only

Total Ban*

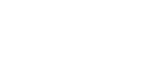

Reduction in GNP (8)

.006
.007
.018
$.035 *$

Reduction in Nuclear

Electric Capacity

(annual quads of

energy inputs processed)

Moratorium

No New

old only

Total Ban
4.04
4.44
8.02

8.02
10.13
Reduction, in Gross

Investment $(\%)$

4.3
4.7
8.1
9.2

Increase in Coal

Steam Capacity

(annual quads of

energy inputs processed)

$$
\begin{aligned}
& 3.70 \\
& 4.06 \\
& 7.24 \\
& 9.05
\end{aligned}
$$

Increase in Personal Consumption Expenditures ( 8 )
0.9
1.0
1.7
$2.0 *$

Increase in Domestic Coal Production (quads)

* See text for comment. These estimates assume resources presently embodied in existing nuclear plants would be reallocated to alternative uses. Allowance for waste of these resources increases resulting GNP reduction another .100 \% to $.135 \%$.

Source: Model results relative to the Base Case BNL projections listed in Tables I.1 and I.2. 
limit consumption increases and investment decreases below the estimates indicated in Table I.3.

Slightly less coal steam electric capacity would have to be provided by 1985 than the amount of Base Case nuclear capacity being replaced, as aggregate electricity production and consumption would decline slightly. This decline in electricity production and consumption is related to two causes. First, the production of consumer goods and services requires less electricity than the production of capital goods, and second, direct fuels are substituted for electricity in providing space and process heat. This substitution results from a small increase in the average price of electricity ( $3 \%$ in the old Only policy case).

All these changes were estimated under the assumption that sufficient time exists between 1976 and 1985 to accommodate these structural shifts. The average annual growth rates in coal and coal steam electric capacity which would be required to accommodate these shifts are listed in Table I.4. As can be seen, the feasibility of the shift from nuclear to coal depends very much on which Base Case 1985 Forecast is used as a reference. If the BNL 1985 Base Case projections are used as a reference, the required growth rates for coal and coal electric capacity would be moderate, even for the Total Ban policy case. However if the FEA Base Case projections are used as a reference, the required average annual growth rates increase to $7.5 \% / \mathrm{Yr}$. for coal and $10.0 \% / \mathrm{yr}$. for coal steam electric capacity for the Total Ban policy case. According to a Hudson Institute study (2), coal production could expand at an average rate of $10 \%$ per year only under "wartime mobilization" conditions. Even if coal production could be increased at these required rates, achievement of the required rate of expansion of coal electric capacity would be difficult for 
Table I. 4

Coal and Coal Electric Capacity Requirements

for Coal Response Case, 1974-1985

Required Average Annual Growth Rates, 1974 to 1985, In Coal and Coal Steam Electric Capacity Production For Alternative Nuclear Policies and Alternative 1985 Base Case Energy Frojections.

\begin{tabular}{|c|c|c|c|c|}
\hline \multirow[b]{2}{*}{ Nuclear Policy } & \multicolumn{2}{|c|}{ Coal Consumption } & \multicolumn{2}{|c|}{ Steam Electric Capacity Ex } \\
\hline & $\begin{array}{c}\text { BNL } 1985 \\
\text { Base } \\
(8 / y \mathbf{y} .) \\
\end{array}$ & $\begin{array}{c}\text { FEA } 1985 \\
\text { Base } \\
(\% / y r .) \\
\end{array}$ & $\begin{array}{c}\text { BNL } 1985 \\
\text { Base } \\
(\% / y r .) \\
\end{array}$ & $\begin{array}{c}\text { FEA } 1985 \\
\text { Base } \\
(\% / y r .) \\
\end{array}$ \\
\hline Base Case & 0.9 & 4.1 & -1.5 & 5.5 \\
\hline Moratorium & 3.0 & 5.6 & 2.3 & 7.6 \\
\hline No New & 3.2 & 5.8 & 2.6 & 7.8 \\
\hline old only & 4.6 & 6.9 & 4.9 & 9.3 \\
\hline Total Ban & 5.4 & 7.5 & 6.1 & 10.0 \\
\hline
\end{tabular}

Source: BNL model results applicd to 1974 and 1985 Energy Projections listed in Table I.1. 
large nuclear cutback amounts. Currently an 8 to 10 year time lag exists between initial plans and start-up operations for coal steam electric plants. To facilitate the expanded coal production, railroad transportation and/or coal pipeline facilities would also have to be greatly expanded. This would be particularly difficult in the New England region.

Intermediate Supply Case 2: "Imported Oil" - Selected energy and economic effects of expanding oil imports and additions to oil steam electricity oapacity and simultaneously contracting uranium production and additions to nuclear electric capacity are presented in Table I.5. The associated GNP reductions, listed in coluriu (1), aro approximately $70 \%$ greater than those estimated in the coal response case for the corresponding nuclear policies. This differential results from the greater costs (both direct and indirect) of producing electricity via oil than via coal.

Aggregate economy-wide gross investment requirements decline sharply but by smaller amounts than those occurring in the coal response case. While baseloaded oil steam plants are less capital intensive than base-loaded coal plants, some additional investment wuld also be required to produce capital-intensive exports which, in turn, would be required to pay for increased amounts of oil imports. Aggregate consumption increases slightly due to the decline in investment requirements. Increased exports are required to pay for the increased amount of oil ịmorts.

Future post-1985 growth rates of consumplion would also be lnwered if oil is used to replace uranium in generating electricity, as the operating costs of nuclear plants are less than those of oil-fired plants. These estimates for changes in GNP and its components are based on a assumed $\$ 9.00 /$ barrel price 
Table I.5

Selected Energy and Economic Effects of the Imported oil

Response Case to Alternative Nuclear Policies

(All Changes Relative to Estimated 1985 Base Case Amounts)

\section{Nuclear Policy}

Moratorium

No New

old only

Tota: Ban*

\section{Reduction in GNP}

.0108

.0128

.0318

$.053 \% *$

Reduction in Nuclear

Electric Capacity (an-

nual cuads of energy

inplts processed)

\section{Moratorium}

No $N \in W$

old only

Total Ban
4.04
4.44
8.02

10.13
Increase in Personal Consumption Expenditures

$$
\begin{aligned}
& 0.5 \% \\
& 0.5 \% \\
& 0.8 \% \\
& 0.9 \%
\end{aligned}
$$

Reduction in Gross Investment

$$
\begin{aligned}
& 4.0 \% \\
& 4.4 \% \\
& 7.5 \%
\end{aligned}
$$$$
8.4 \% \text { * }
$$

Increase in Oil Imports (quads)
Increase in Oil Electric Capacity (annual quads of energy inputs processed)

$$
\begin{aligned}
& 1.56 \\
& 1.93 \\
& 5.30 \\
& 7.28
\end{aligned}
$$

*These estimates assume ressurces presently embodied in existing nuclear plants would be reallocated to alternative uses. Allowances for waste of these resouces increases the GNP reduction.another.100\% to .153\%.

Source: Model results relative to BNL 1985 Base Case energy and economic projections presented in Tables I. 1 and I.2. 
for imported oil (in 1974\$). Should the price of oil be greater in 1985, as recent trends indicate, the GNP reductions would be larger, the investment reductions would be smaller, and there would be little change in aggregate consumption.

Assuming the domestic production of oil remains constant, oil imports in 1985 would increase by 9.9 quads for the Total Ban policy, while uranium consumption would decrease by 10.1 quads. For all nuclear policies, oil steam electric capacity requirements increase less than those for oil imports, since oil is substituted for electricity in generating space and water heat. The price of electricity increases by $6 \%$ for the Total Ban policy case, excluding any further rise in price required to compensate utilities for debt payments associated with the wasted nuclear capacity. If utilities were allowed to include wasted nuclear construction costs in their 1985 rate base, the electricity prices would increase $10 \%$ for the Total Ban policy.

Intermediate Demand Response Case: "Conservation" - In this response case, the various heating, cooling, lighting, motive power, and feedstock requirements of industry and consumers were all cut back proportionately, by an amount sufficient to offset declines in nuclear electricity production, givon gome simultaneous substitution of direct fuels for electricity. That is, by assumption, GNP was kept constant, and the model was solved for the resulting proportionate reduction in energy demands which would be required to offset the different nuclear cutback amounts.

These energy demand reductions are listed in 'l'able I.6. They range from 6.5\% for the Moratorium case to $17.0 \%$ for the Total Ban case. For each nuclear poliry case, the decrease in required energy demands is less than the reduction in electricity output, as some oil and gas is used in place of electricity to 
Table I.6

Selectec Energy and Economic Effects of the Conservation Response Case to Alternative Nuclear Policies

(All Changes Relative to Estimated 1985 Base Case Amounts)

\section{Nuclear Policy}

Moratorium

No Nəw

Old Dnly

Total Ban
Reduction in Energy Demands

Required to Keep GNP Constant

$6.5 \%$

8.0

14.48

$17.0 \%$
Reduction of BTU's of

Electricity output

9.58

11.78

17.58

30.18
Reduction of BTU's of Electricity Capacity

12.38

14.78

21.28

$34.8 \%$
Increase in Personal Consumption Expenditures

(Net of Energy Purchases)

Moratorium

No New

old only

Total Ban
$1.4 \%$
$1.6 \%$
$2.3 \%$
$2.5 \%$
Reduction in Gross

Investment

$6.4 \%$

$7.5 \%$

$10.8 \%$

$11.5 \%$ 
meet heating demands. Electricity output, in turn, decreases less than the aggregate amount of electric generating capacity input, as the remaining nonnuclear capacity is used more intensively.

If the old only nuclear policy was adopted, approximately \$115 billion (in constant 1967 \$) less of additional resources would be spent on the construction and operation of nuclear plants over the 1976 to 1985 period, while in 1985, gross investment requirements (both direct and indirect) would decline 10.8\% from the Base Case amount, as shown in column (5) of Table I.6. These resources, in turn, could be reallocated toward increasing the production of other goods and services. If all the resources were so reallocated, personal consumption expenditures, net of energy purchases, would increase at most by $2.3 \%$ in 1985 , as indicated in column (4), under the limiting assumption that decreased industrial energy purchases would not decrease industrial production efficiency.

To limit decreases in industrial efficiency and in consumer satisfaction resulting from less energy consumption, much of the increased non-energy production would have to be devoted toward increased pruduction of such energy saving goods and services as insulation materials, smaller, lighter automobiles, and more energy efficient electric appliances. Considerably more research is required before any conclusions can be reached as to the payoff obtained from reallocating resources from energy production toward energy conserving activities.

Analysis of Model Results

The estimated relationship between GNP reductions and associated nuclear cutbacks are shown in Figure I.I for both the coal and imported oil response cases. In both, substitution of oil and gas for electricity in meeting heating 


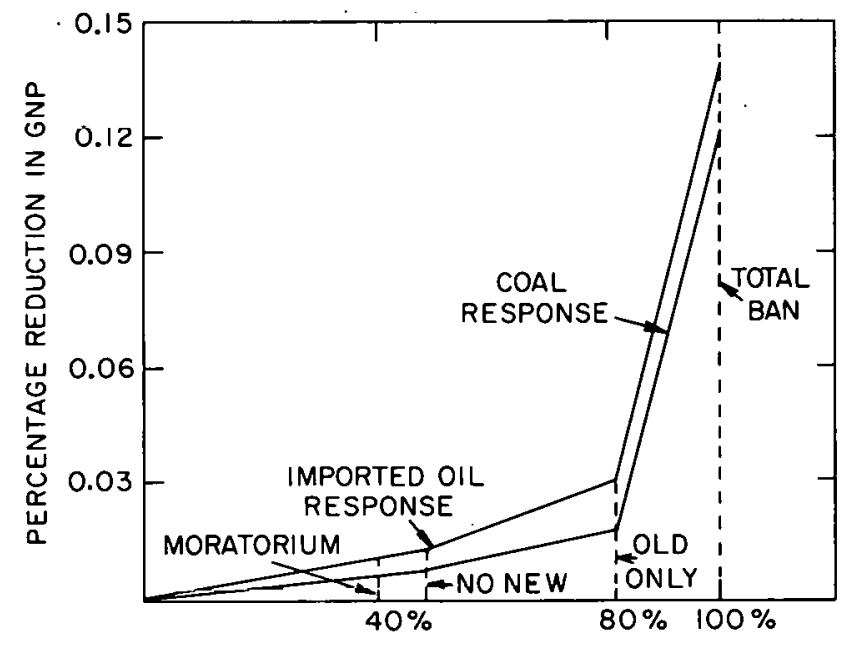

PERCENTAGE REDUCTION IN NUCLEAR CAPACITY

Figure I.1. Percentage reduction in 1985 GNP for alternative nuclear policies and supply responses. 
demand limits the economic cost of small declines in nuclear capacity. However this substitution mechanism is quickly exhausted so that large declines in nuclear capacity necessitate correspondingly greater increases in oil or coal electric capacity expansion. If the 1985 Base Case amount of nuclear capacity was cut back by more than 808 , nuclear capacity currently in place would also have to be scrapped, leading to much sharper GNP reductions.

Several other factors, not explicitly considered in the analysis, would further increase the non-linearity between the amount of the nuclear cutback and the resulting GNP reduction estimated for each of the two supply alternatives considered. Some increase in average operating rates of existing capacity could be achieved by both delaying maintenance and by adopting incentive mechanisms to smooth out the time pattern of electricley consumptiul. Tlese actions would further limit the economic costs of small decreases in nuclear capacity, but would have less proportionate offsetting impact for large decreases in nuclear capacity.

The lack of regional detail in the models used may have biased the results as follows: the relation between nuclear culdadks and GNF reductiono for both the coal and imported oil responses were estimated using estimated 1985 national average costs for coal, imported oil and nuclear inputs. However, the delivered cost and availability of imported oil and particularly of coal vary considerably by region. Since in lite alsence of any nuclcar moratorium policies, nuclear plants will tend to be installed in those regions where the cost advantage of nuclear plants over oil or coal burning plants exceeds national average cost differentials, the costs of switching from nuclear to coal or oil plants in these regions would exceed the national aver- 
age cost differential. Thus the GNP decreases associated with the imported oil and the coal response cases would in fact be greater than estimated.

Also, to the extent that the national average prices of coal and imported oil would have to increase so as to bring forth more coal or imported oil, (i.e. if the supply elasticity of domestic coal production and of oil import availability was less than infinite), the economic costs in the form of GNP rcductions would be greater than estimated. However even if the 1985 GNP reductions estimated by the model are doubled, the largest GNP reduction would be less than $.21 \%$ for a Total Ban nuclear policy with an imported oil response. In addition, any conservation response, in combination with oil or coal responses, might reduce GNP impacts of nuclear policies.

In summary, as long as the 1985 nuclear shortfall amounts can be offset by some combination of the imported oil, coal and conservation responses, the impact of the nuclear cutback and the associated response on GNP in 1985 will be small. However other public policy variables besides GNP will be adversely affected by nuclear cutbacks. If imported oll is used as a replacement for nuclear electricity inputs, oil imports will increase up to 9.9 quads in the Total Ban case, while if coal is used as a replacement, greater amounts of coalrelated environmental damages, such as sulfur oxide and particulate emissions, will result. Further, this study estimates GNP decreases which would occur only in 1985, while decreases would occur over a period of many years.

Some mention should be made of a third potential intermediate term supply alternative not explicitly considered in Lhis analysis. Should nuclear reduction policies he adopted, utilitics may well ald base-loaded oil burning gas turbine plants as replacements for planned nuclear plants, since the lead time required for the installation of gas turbines currently is considerably less 
than those required for either coal or oil steam plants. Since gas turbines require 40 - $50 \%$ greater amounts of oil than oil steam electric capacity to generate an equivalent amount of electricity, the cost of this response would be great.

In addition to the above analyses which permitted compensative energy supply and demand responses to nuclear reductions, an analys is is also made as to what affect decreases in nuclear capacity would have on the 1985 economy assuming that: 1) no increàses occur in Base Casc amounts of non-nurelear electric capacities, and 2) that energy demand requirements per unit of output and consumption remain constant at Base Case amounts. This case can be interpreted in two ways. First, it can represent a "sudden severe nuclear accident case" occurring in 1985, in which some or all of the existing 1985 nuclear capacity is shut down with no advance notice. Allernatively, with some adjustment, it can be interpreted as an extension of the 1976 nuclear policy analysis in which, because of shortages, bottlenecks and poor planning, it is not possible to expand alternative electric capacities at required rates nor decrease Base Case energy consumption demands voluntarily via price increases and/or end-use capital stock adjustments.

The effects of this policy on GNP, consumption and investment are shown in Figure I.2, under the further assumption that electricity sales to consumers and producers all decrease prupurtionately. The indicater shanges in GNP, consumption and investment are all much larger than those estimated for the coal and imported oil responses. A $40 \%$ reduction in the 1986 Base case anuml of nuclear capacity would reduce GNP by 5\%, while a $100 \%$ reduction in nuclear capacity would reduce GNF by 30\%. In all probability several additional policies not considered in this analysis would reduce the magnitude of these GNP reduc- 


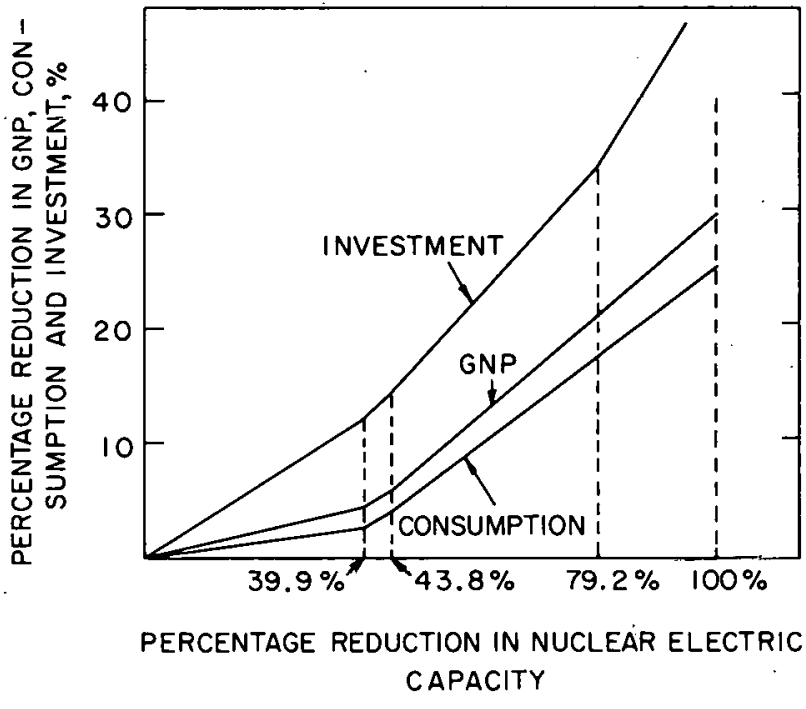

Figure I.2. Curtailment Case: Percentage reduction in $1985 \mathrm{GNP}$, consumption and investment resulting from reductions in 1985 nuclear capacity avallability. 
tions. For example, utilities would increase the operating rates of plants previously used for temporary peak demands, while curtailing "non-essential" peak demands such as residential and commercial air conditioning. However, relative to the previous intermediate term response cases analyzed, the impact of any given sized nuclear cutback would still be large. Implications of Results for Public Policy

1) Implementation of any nuclear mortorium policy must be accompanied by policies designed to encourage the expansion of alternatives to nuclear energy. The costs of failing to provide for alternatives will be large and will increase more than proportionately to the amount of uncompensated nuclear shortfall. The $1985 \mathrm{GN}$ would decrease up to $30 \%$ with an uncompensated $100 \%$ nuclear shortfall, and up to $5 \%$ with a $40 \%$ shor lfall.

2) To keep potential future costs to a minimum, decisions as to the future of nuclear electricity should be made as quickly as possible. In particular, the current surplus of electricity generating capacity should not be used as an excuse to delay decisions. For large nuclear cutbacks, significant reallocation of resurures will be required ln urder to achieve indicated expansion rates in non-nuclear electricity capacity, coal production, and/us ill imports. In order to achieve the required reallocation of resources, immediate planning with respect to capital decisions will be required. Even conservation alternatives w $\perp \perp$ requlıe clianges in the nature of enerqy using capital equipment, and most of these changcs can only he implemented gradually over time as existing capital stocks are replaced.

3) If available time and private motivation permits sufficient implementation of some combination of coal, imported $n i l$ and conservation alternatives to nuclear power, than the economic cost of nuclear moratoria legislation will be 
small. Even if all nuclear production is abandoned by 1985 , including production from existing capacity, the 1985 GNP would decrease by less than one half of $1 \%$.

4) These results do not yield any judgement as to the desirability of halting nuclear production of electricity. This study only considers the economic impact of such actions. Before any overall judgement can be made, social, environmental and political considerations must be considered. Some of these considerations are briefly raised in Chapter VI. 


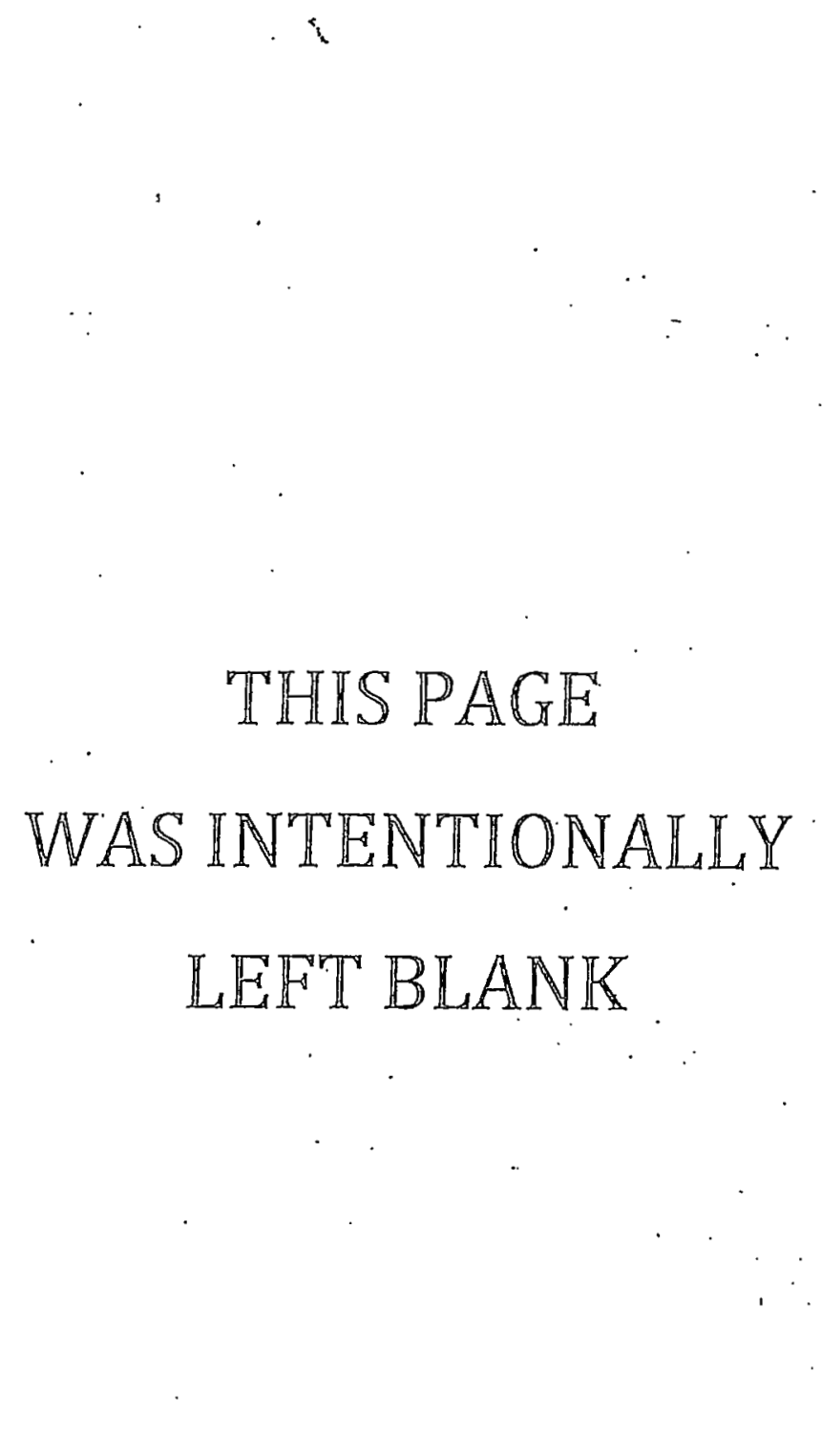


Chapter II. Estimation of the Relationship Between Electricity, Energy, and the Economy

\section{Introduction}

This study of the potential effects of decreases in nuclear electric generating capacity on the 1985 economy is one application of a more general framework for analyzing the relationship between energy and the economy. Depending on the particular assumptions employed, the framework can be used to estimate the immediate impact of unexpected decreases in energy supply, such as we recently experienced during the OPEC oil embargo, as well as the long run impacts of supply decreases under conditions of perfect knowledge and perfect factor mobility .

Importance of Assumptions Concerning Substitution Mechanisms

In order to illustrate the methodology graphically, highly restrictive assumptions as to possible substitutions are employed in order to highlight important relations existing between energy, GNP, and employment. Then these restrictive assumptions are gradually relaxed and the effect of the relaxation on the solution is indicated. First, let us assume that: 1) only two inputs, energy and labor, are required to produce GNP; 2) the technology used to combine labor and energy in the production of GNy is of the "putly., clay" varicty -that is, before any technology combining labor and energy is actually introduced, such a wide variety of technological processes are available that energy and labor are perfect substitutes for one another in the production of GNP; but once introduced, they become perfect complements; 3 ) energy is used only as an input into the production of GNP -- it is not a part of GNP itself; 4) that the aggregate supplies of future labor and energy inputs are known with certainty; 5) that neither the supply of labor nor the supply of energy inputs are price 
dependent; and 6) that the economy starts from a position of full utilization of all available energy and labor.

Given these six assumptions, assume the economy starts from a position $A$ in Figure II.I where 74 quads of energy and 88.7 million man-years of labor are used to produce $\$ 839.2$ billion worth of GNP (in constant 1958 dollars). This approximates the position of labor, energy, and GNP in 1973, prior to the OPEC oil embargo. Given assumption 2, however, household and business location patterns and industrial processes could have been historically oriented so that, by 1973, positions B or C would also have been obtainable, and, if obtained, would have yielded the same GNP. Thus, line BAC represente the ex ante iso." quant for the production of $\$ 839.2$ billion of GNP which was available to society in the past, while $\mathrm{OB}, \mathrm{OA}$, and $\mathrm{OC}$ represent the alternative expansion paths of $\mathrm{E}$ and $\mathrm{L}$ which were open to society to get to $\mathrm{B}, \mathrm{A}$, or $\mathrm{C}$ respectively. In 1973, society is limited ex post to a series of rectangular isoquants along $O A$, as in Figure II.2, since past locations and process decisions have already been made and are embodied in the capital structure (roads, buildings, blast furnaces, etc.) of the economy. Given assumption 2, as long as this capital structure remains constant, specified fixed amounts of energy and labor are required per unit of GNP produced. That is, increases in only nne innut cannot increase GNP. To increase GNP, increases in both inputs are required.

LIkewlse, decreases in either input will lead to underutilization of the other input and a decrease in GNP. In Figure II.2, if E decreases from $E_{1973}$ to Eembargo' the utilization of $\mathrm{I}$ will decline from $\mathrm{L}_{1973}$ to $\mathrm{L}_{\text {embargo' the }}$ economy will shift to a lower isoquant, and GNP will decline. Assuming constant relurns lu scale, any given percentage decline in energy, (equal to $100 \cdot \frac{\Delta E}{O E}$ in Figure II.2) will cause the same percentage decline in labor utilization 


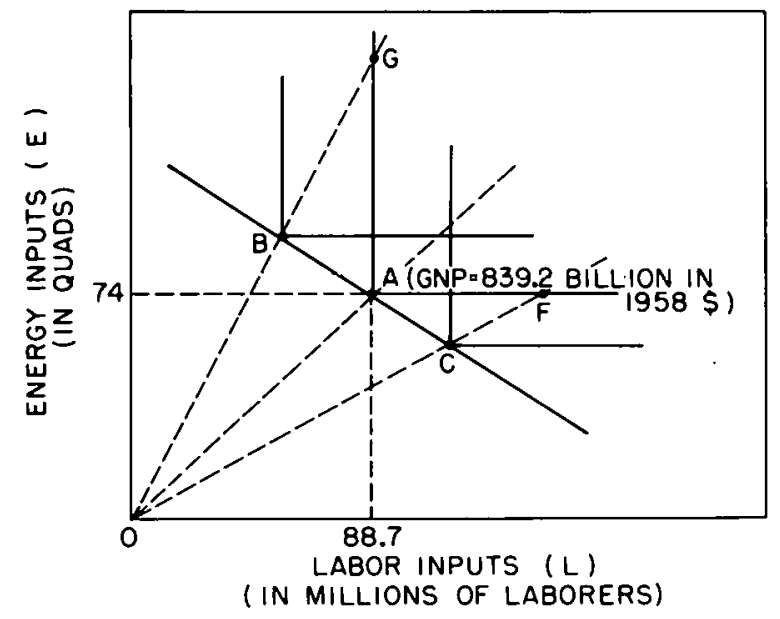

Figure II.1. Energy, employment and GNP relationships, generalized.

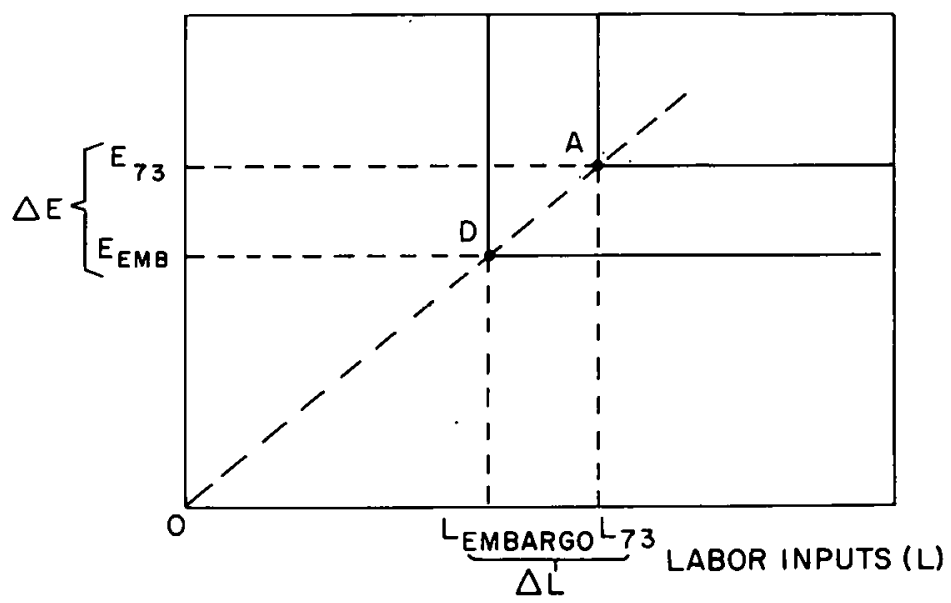

Figure II.2. Energy, employment and GNP relationships, limited ex post. 
(equal to $100 \cdot \frac{\Delta \mathrm{L}}{\mathrm{OL}}{ }_{1973}$ ), and in GNP (equal to $100 \cdot \frac{\mathrm{AD}}{\mathrm{OA}}$ ). Society now wishes it had chosen an expansion path such as OC in Figure II.l which utilizes more labor relative to energy. But it is too late.

When the six assumptions on which the above analysis was based are relaxed, the impact of a decline in one input on GNP and employment becomes less than proportional. Some technical substitution of labor or other inputs for energy is possible, even ex post, so that short run ex post production functions are not perfectly rectangular. Motivation for making factor substitutions will occur under a free market system if factor supplies are price responsive. With the decline in $\mathrm{E}$, surpluses of $\mathrm{L}$ relative to $\mathrm{E}$ will drive the price of $\mathrm{E}$ up relative to the price of $\mathrm{I}$. Cost minimizing behavior will then lead producers to substitute labor for energy. Likewise, if more than one output is considered, under perfect market conditions, energy shortages will drive the prices of energy intensive outputs up relative to those of less energy intensive goods, and consumers will buy more of the less energy intensivc goods, thus decreasing energy requirements per unit of aggregate GNP. Slibstitution Mechanisms Employed in Other Models

Mathematical and econometric models currently being used to analyze the relationships between energy and the economy vary tremendsusly in the assumptions they make as to the amount of factor and product substitution which is possible in production and consumption. At one extreme, the Hudson-Jorgenson Energy Interindustry model (3) incorporates possibilities for all such substitutions so that changes from expansion paths are possible both ex post and ex ante. In addition utility maximizing consumer behavior and profit maximizing producer behavior are also assumed to exist in this model, so that motivation for such substitution also exists whenever relative prices change. At the 
other extreme, conventional fixed coefficient input-output models do not allow for any input substitution in response to changes in relative prices. In addition, when input-output models based on historical input-output coefficients are used in forecasting, future ex ante expansion paths will equal the ex post expansion paths previously observed, regardless of the path of future energy prices over time.

Substitution Mechanisms Employed in This Study

The approach used in this study is to start with a conventional inputoutput model, and then to modify the model so as to permit an analysis of the following types of substitution possibilities.

1) Inter-fuel Substitution with Given Energy Requirements per unit of GNP - With a cutback in the amount of electric generation capacity, it may be possible to substitute coal, oil or gas for electricity in meeting given demands for energy in the form of heat, light, and power. Given sufficient interfuel substitution possibilities, deçeases in GNP and employment will be related to the aggregate cutback in all energy inputs, rather than just to the cutback in the inputs associated with electricity production.

2) Substitution of Alternative Electric Generation Capacities and Primary Fuels for Uranium and Nuclear Electric Generating Capacity - In this study, the two most likely near term substitutes for uranium and light water reactors are considered: these are coal and coal steam electric capacity, and imported oil and oil steam electric capacity.

3) Substitution of Non-Energy Goods and Services for Energy - with a given cutback in electricity and energy inputs, it may be possible to substitute such non-energy inputs as lighter automobiles and insulation materials for fuel and electricity inputs. The magnitude of this substitution mechanism 
depends both on technology and the time allowed for implementation. The model used in this study explicitly incorporates the first two types of substitution possibilities while model parameterization techniques were employed to analyze the third type.

The next chapter describes the mathematical models which were used first to estimate the 1985 Base Case structure of the economy. An explanation of the extent to which each of these substitution mechanisms might compensate for cutbacks in nuclear electric generating capacily and limit dcolines in GNP and employment is contained in subsequent chapters. 
Chapter III. Description of Combined Input-Output Linear Programming Model

The two-level iterative model employed in this study is described in detail in (4). The general outline of the model is illustrated in Figure III.l. A 110-sector input-output model, shown in the bottom half of Figure III.I, is used to estimate a vector of total outputs, $x$, given a matrix of current inputoutput coefficients, A, and a vector of final demands, Y. The 110 sectors are divided into three categories: energy supplies, $s$, including both raw fuels (e.g. coall and converted energy forms (e.g. synthetic fuels); functional energy forms, or products, p, (e.g. space heating); and all other sectors, m. The outputs of all $\mathrm{s}$ and $\mathrm{p}$ sectors are measured in terms of BTU's, while those of the $\mathrm{m}$ sectors are measured in terms of constant 1967 dollars.

The Brookhaven Energy System Optimization Model (BESOM), shown in the top half of Figure III.l, is used to estimate that pattern of intermediate energy forms, $z$, which minimizes the total cost of all energy supply and conversion activities, subject to four types of restrictions: 1) that the amount of primary raw fuels used is less than or equal to the available supplies, $b_{u}$; 2) that the amount of converted energy produced for end use requirements is equal to the amount required, $b_{v}$; 3) that the amount of environmental pollutants produced is less than or equal to a specified amount, $b_{w}$ and 4) that the amount of fuel used for a particular conversion or end use device is less than or equal to the capacity of that device, $b_{y}$, where capacities are defined in terms of maximum rates of flow of energy input.

'l'he two models are solved iteratively. Energy product outputs from the I-O solution, after some disaggregation, are inserted as the $\mathrm{b}_{\mathrm{v}}$ end use requirements in BESOM. That is, $b_{v}$ is an endogenous vector in the combined model. 


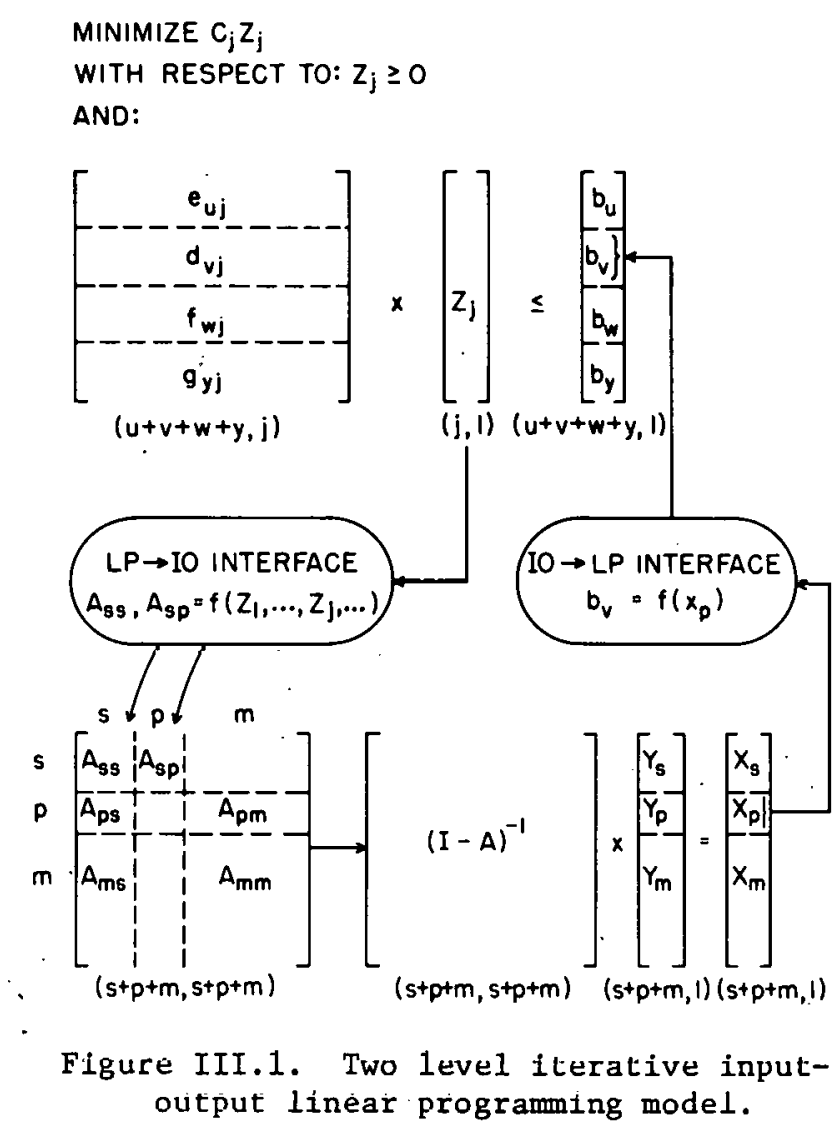


Also, from the minimum cost BESOM solution vector of intermediate energy flows, $z_{j}$, corresponding energy supply to energy product coefficients are computed and inserted as the $A_{S S}$ and $A_{S P}$ submatrices of $A$. Thus the values of the coefficients in the $A_{S S}$ and $A_{S p}$ matrices are endogenous in the combined model.

In solving the combined model, arbitrary initial values of the $A_{S s}$ and $A_{S p}$ coefficients are used. A solution is reached when values of the $A_{S S}$ and $A_{s p}$ coefficient variables converge. If realistic initial values of $A_{S s}$ and $A_{s p}$ are used, convergence within 0.18 is usually reached after three iterations. Solution values of $A_{\text {Ss }}$ and $A_{\text {sp }}$ are invariant with respect to the initial values chosen to start the iterative solution procedures.

A list of all the endogenous and exogenous variables is shown in Table III.1. Definitions of all these variables are contained in (5), with the following exceptions. The $b_{u}^{\prime}$ and $b_{y}^{\prime}$ variables refer to the actual amount of energy supplies, $u$, and energy conversion equipment capacities, $y$, used in an optimal solution. That is, $b_{u}^{\prime} \leq b_{u}$ and $b_{y}^{\prime} \leq b_{y}$. Likewise, $b_{w}^{\prime}$ refers to the amount of pollutants actually produced, and $b_{w}^{\prime} \leq b_{w^{*}}$. The $\lambda$ variables refer to shadow prices on the right hand side variables. Each $\lambda$ variable measures that amount by which the objective function cost would decrease if one more unit of the resource were available.

For this study, estimates of the exogenous $A$ sub-matrices and the $y$ tinal demand vector were obtained independently from several growth models. These estimates, along with the estimating procedures used to obtain them are presented in $(5) . *$

*Currently the combined I-O - LP model used in this study is being tied to the Hudson-Jorgenson inter-industry molel (3), so that the $A_{p s}, A_{p m}, A_{m s}$ and $A_{m m}$ coefficients, and the 110-order vector of final demands, $y$, after aggregation into a smaller number of sectors, will become endogenous with respect to relative prices. For a description of this model linkage, see (7-9). 
Table III.I

Classification of Variables Contained in Combined IO-LP Model

Endogenous

$A_{\text {SS }}$

${ }_{\text {Ap }}$

$x_{s}$

$x_{p}$

$\mathrm{X}_{\mathrm{m}}$

$b_{v} \quad$ Primal LP Solution

I-O Solution

$x^{p}$

$b_{u}^{\prime}$

$\mathrm{b}_{\mathrm{u}}^{\prime}$

$b_{y}^{\prime}$

$\lambda_{\text {i }}$

$\lambda_{\mathrm{v}}$

$\lambda_{\mathrm{w}}$

$\lambda_{y}$

\section{Exogenous}

A ps

$\Lambda \mathrm{pm}$

A ms

I-O Model

$\mathrm{A}_{\mathrm{mm}}$

$Y_{S}$

$Y_{p}$

$Y_{\mathrm{m}}$

$c_{j}$

e uj

$d_{v j}$

$f_{w j}$

LP Model

$g_{y j}$

$b_{u}$

b

by 
For this study, the combined model, illustrated in Figure III.1, on page 32, was made dynamic with respect to time and capital requirements by employing a simple accelerator model. It was assumed that all outputs grow at steady state growth rates, that capital/output ratios remain fixed over the 1975-1985 time frame, and that the industrial composition of the new capital stock is constant. As part of the estimated 1985 final demand vector, $Y$, estimates of gross private fixed domestic investment, $I_{85}$, were obtained from (6). This $I_{85}$ vector presents a snapshot picture of the origin of business durable capital equipment and construction transactions by selling sector. It was assumed that the structure of this vector remains constant.*

The level of $I_{85}$ represents an estimate of the amount of capital going either to replace depreciated capital equipment or to net additions to the capital stock. This sum was independently estimated by the following accelerator model.

The level of gross investment for each sector from 1984 to 1985 can be determined as follows: By definition of gross investment, $I_{85}(i)$ :

$$
I_{85}(i)=K_{85}(i)-K_{84}(i)+\delta(i) K_{84}
$$

$$
\begin{aligned}
& \text { where } \delta(i)=\text { depreciation rate of capital in sector (i) } \\
& \text { and } K(i)=\text { the amount of capital stock in sector (i) }
\end{aligned}
$$

\footnotetext{
*Eventually, a full capital coefficient matrix will be used instead of capital output ratios, so that both the level and structure of investment will be endogenous.
} 
Assuming $c(i)$ remains constant over time, by substitution,

$$
I_{85}(i)=c(i) x_{85}(i)-c(i) x_{84}(i)+\delta(i) c(i) x_{84}(i)
$$

where $c(i)=\frac{K(i)}{x(i)}$.

Now assume a steady state rate of growth of output, $g$ (i), between a base year (1967 values were used) and 1985 for each sector i. Then

$$
g(i)=\frac{1}{18} \ln \frac{x_{85}(i)}{x_{67}(i)}
$$

and

$$
x_{84}(i)=\frac{x_{85}(i)}{1-g(i)}
$$

and by substituting (4) in (2):

$$
I_{85}(i)=r(i) x_{85}(i)-\subseteq(i)[1-\delta(i)] \frac{x_{85}(i)}{\overline{I+g(i)}}
$$

U. sLuplifying

$$
I_{85}(i)=c(i) x_{85}(i) \quad\left[1-\frac{1-\delta(i)}{1+g(i)}\right]
$$

The above investment accelerator model was linked with the static I-O - LP model by the following iterative solution procedure. First, given initial values for $I_{85}$, estimates of $x_{85}(i)$ were obtained from a combined I-O - LP model solution and inserted in (3) to obtain $g(i)$. Then, given $g(i)$ and $x(i){ }^{\prime}$, and 
exogenous estimates of $\mathrm{c}(i)$ and $\delta(i)$, (6) was solved for $I_{85}(i)$. If the sum of $I_{85}(i), \sum_{1} I_{85}(i)$, from (6) differed from the sum of the initial vector $I_{85}$ that initial vector was scaled accordingly to equal $\sum_{I} I_{85}(i)$ from $(6)$, and the PCE vector, C, was scaled so that $C+I$ remained constant. The procedure was, repeated until convergence was achieved. In all cases, four iterations achieved convergence within . .18 . 
THIS PAGE

\section{WAS INTENTIONALLY LEFT BLANK}


Chapter IV. Estimation of 1985 Base Case Model Parameters

Introduction.

Values of outputs, prices and other endogenous variables are estimated primarily as a reference point against which outputs and prices of the various response solutions are compared. However the magnitude and feasibility of changes associated with the various response mechanisms often depend on the base case solution values themselves. Obviously, the effects of any nuclear moratorium will be smaller the greater the estimates of other non-nuclear types of future energy supplies and the smaller the estimates of future energy demands. For this reason much care was taken to make the 1985 estimates of the exogenous variable as "reasonable" as possible, where reasonable is interpreted to mean estimates both supportable by referenced analyses and estimates approximately near the median magnitude of all available 1985 estimates. However since future energy policies are most uncertain, as are the long run consumer reactions to higher absolute and relative prices for energy, any point forecast of the future is subject to large and uncertain errors. For this reason, results obtained from the nuclear impact analyses are compared to both the 1985 Base case Projections estimated here, and to a set of 1985 Federal Energy Administration estimates ( 1 ).

Seven different sets of exogenous parameters were estimated for insertion into the combined IO-IP model. An explanation of the derivation of these parameters follows. These parameters were then inserted in the combined IO-LP model which was then solved for the 1985 Base Case Projections. The reader not interested in technical details may want to skip directly to the discussion of the Base Case Projections themselves, discussed in Chapter V. 
Final Demands and GNP, Net of Energy

The estimation procedures used to obtain the 110-order final demands are presented in (6). The non-energy final demands were derived first by estimating the aggregate growth in GNP, and then by estimating the division of this GNP both by type of final purchaser and by type of industry output purchased. Estimates were made for the following final purchasing sectors: personal consumption expenditures; :gross private fixed domestic investment, changes in inventories, federal government defense purchases, other federal government purchases, state and local government purchases, exports and competitive imports. The aggregate expenditure of each of these purchasing sectors was subdivided into the 110-order industry classification. listed in Table A-I in Appendix A. The GNP was estimated to increase at an average annual rate of $4.25 \% / y r$ between 1975 and 1985 so as to equal \$1439 billion, in 1967 dollars, in 1985. This forecast is based on the assumptions that labor productivity will increase slower than the average post-World. War II rate, but faster than rerent nostr 1968 rates, and that the unemployment rate will return to around $4 \%$. by 1985 . The $4.25 \% / Y r$ GNP growth rate is compared with other recent 1975-1985 GNP growth rate forecasts in Table IV.I and with past historical growth rates in Figure IV.1. In terms of final purchasing sectors, exports, imports, and the business durable purchases component of fixed investment are expected to increase faster than GNP, while government purchases, particularly of highway, school, and . defense-related purchases are expected to increase less rapidly than GNP. The estimated values of the 90 different non-energy final demands are listed in Table A-2 in Appendix A. Estimated 1967 to 1985 percentage changes in final demands at a more manageable 19-order level of aggregation are shown in Figure IV.2. Final demands for industrial materials and capital goods increase 
Table IV.1

Alternative GNP Projections to 1985

Estimated 5 Year Average Annual Growth Rates of GNP and Estimated 1985 GNP in Constant 1958 Dollars

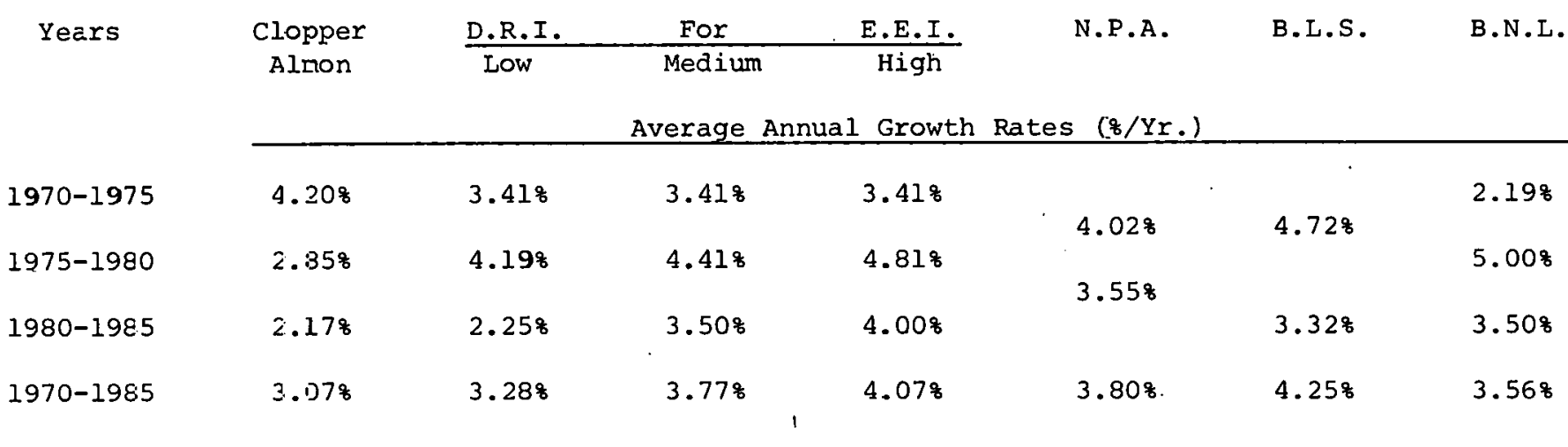

Estimated 1985 GNP (Billions of 1958 \$)

1985

$\begin{array}{lllllll}1135.5 & 1171.8 & 1258.4 & 1314.0 & 1263.6 & 1348.4 & 1220.4\end{array}$

Col (1): Almon, Clopper, Jr. et al., 1985: Inter-Industry Forecasts of the American Economy, D.C. Heath and Company, Lexington, Mass. 1974, November 1973. Forecasts, p. E6.

Cols. $\begin{aligned}(2)-(4): & \text { Edison Electric Institute, Economic Growth, Pricing and Energy Use, Mimeo, Part II, } \\ & \text { Section B. The GNP estimates. Were obtained from Data Resources, Inc. for E.E.I. }\end{aligned}$

Col (5): National Planning Association, The U.S. Economy: 1973 to 1983, N.P.A. Report Number 73-N-1, pp. 30-31. The 1985 GNP was estimated on the basis of an average annual growth rate of $3.55 \% / Y x$ between 1983 and 1985 . 
Table IV.l (Con‡'d.!

Col (6): Bureau of Labor Statistics: U.S. Department of Labor, From 134-order 1980 and 1985 Input-Output For ecasts, unpublished, tape of data available Erom BLS. The $4.72 \%$ is for the entire 1970 to 1980 period.

$\operatorname{col}(7):$ BdL estimates. 


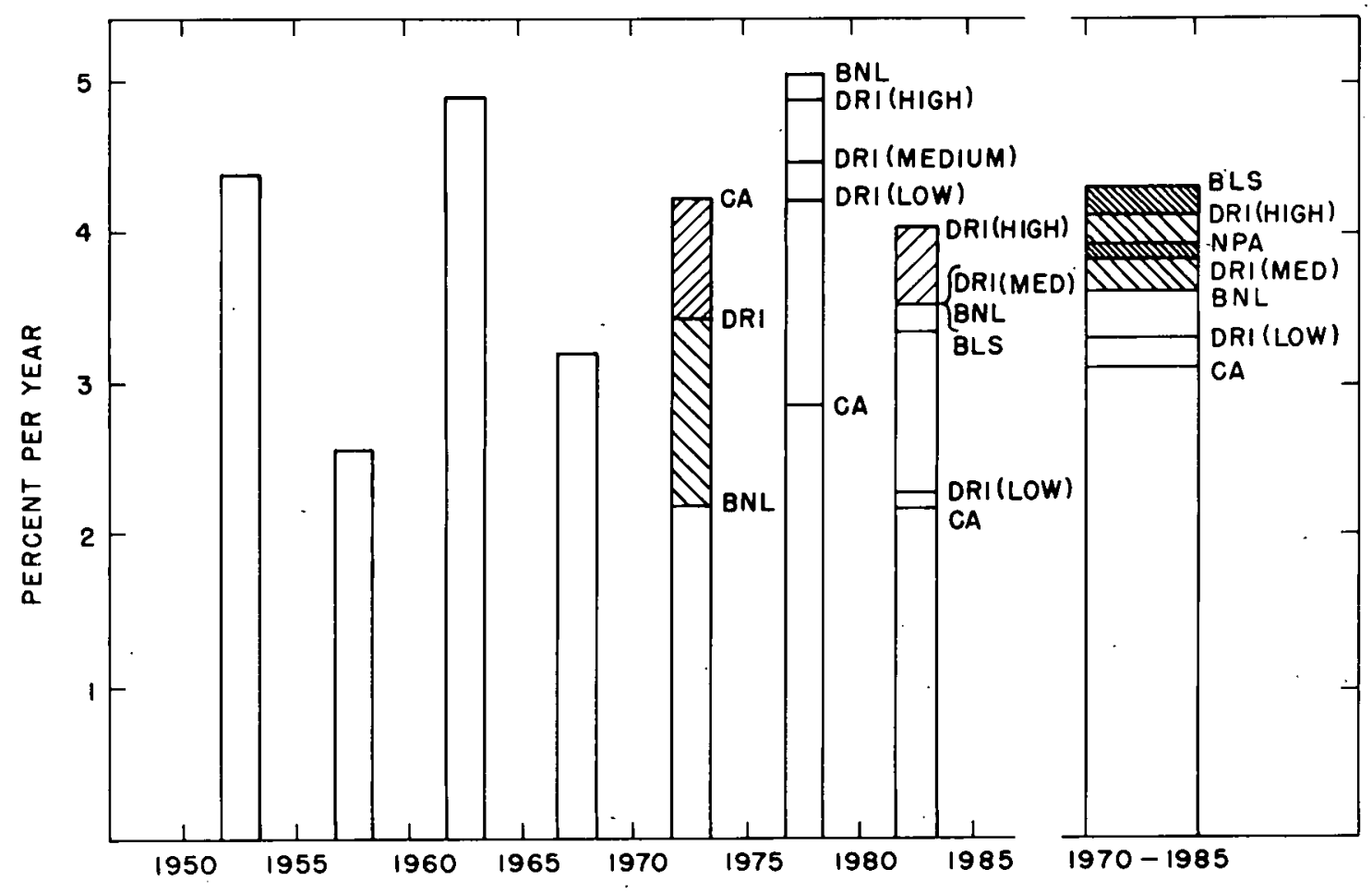

SOURCE: 1950-1970, STATISTICAL ABSTRACT OF THE U.S.1974, TABLE N0.603, P. 375 1970-1985, SEE TABLE I

Figure IV.1. Five year average annual growth rates of GNP 1950-1955 to 19801985 (in constant 1958 \$). 

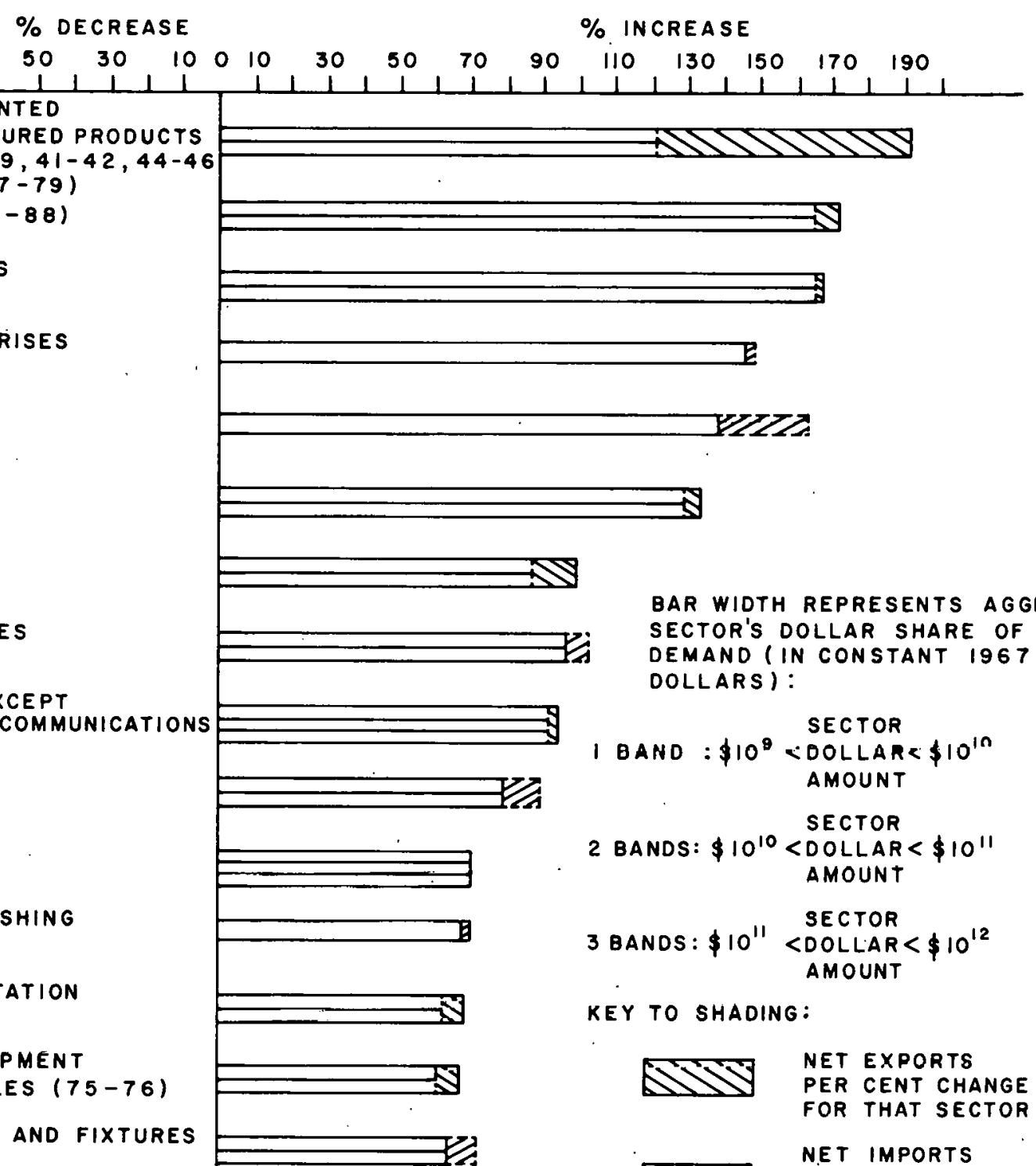
more rapidly than GNP, since these are export-oriented industries, and exports are estimated to increase more rapidly than GNP. Final demands for services also increase more rapidly than GNP, particularly for communications and government services. Final demands for the products of most non-durable consumeroriented industries increase less rapidly than GNP - particularly the food and textile industries. Drugs, cosmetics, and plastic products are exceptions. Energy Product Final Demands

Estimates for all consumer and government final demand energy purchases are measured in terms of BTU's of energy end use products (space heat, water heat, etc.). The estimated 1985 amounts, and the average annual 1967 to 1985 growth rates, shown in Table IV.2, were taken from (6), which in turn used several primary sources, $(10-12)$. For the most part, these growth rates reflect modest reductions from previous historical growth rates due to expected long run consumer responses to higher energy prices. For example, in estimating motive power requirements, it was assumed that the miles per gallon of the automobile stock would rise from 13.1 miles per gallon in 1973 to 17.5 miles per gallons in 1985, and for space heating demands, it was assumed insulation standards on new homes would increase. The 1985 estimates do not assume either government imposed mandatory conservation measures or reductions in energy prices from 1975 levels.

The final demand for air conditioning grows the most rapidly, at an annual rate of $8.8 \%$ per year between 1967 and 1985 . The only other energy demand sector to increase more rapidly than the estimated $3.3 \%$ per year increase in aggregate GNP is the estimated $3.4 \%$ per year increase in lighting and other electric power. In the aggregate, the demand for all energy end uses, in terms of BTU's, 
Table IV.2

Final Demands for Energy Products, 1967 and 1985

\begin{tabular}{|c|c|c|c|c|c|}
\hline $\begin{array}{l}\text { BNL 110-Order } \\
\text { Sector Number }\end{array}$ & Sector Name & $\begin{array}{c}1967 \\
\left(10^{12} \text { BTU }\right) \\
\end{array}$ & $\begin{array}{c}1985 \\
\left(10^{12} \mathrm{BTU}\right) \\
\end{array}$ & $\begin{array}{c}\text { Average Annual } \\
\text { Growth Rate } \\
1967-1985 \\
(8 / \text { yr }) \\
\end{array}$ & $\begin{array}{l}1985 \text { Final Demand } \\
\text { as Percent of } \\
\text { Total Consumption }\end{array}$ \\
\hline 13 & Ore reduction feedstocks & 0 & 0 & -- & 0 \\
\hline 14 & Chemical feedstocks & 94 & 145 & 2.41 & 28 \\
\hline 15 & Motive power & 1,853 & 2,618 & 1.94 & 588 \\
\hline 16 & Process heat & 402 & 522 & 1.46 & 48 \\
\hline 17 & water heat & 874 & 1,203 & 1.79 & $58 \%$ \\
\hline 18 & space heat & 5,536 & 6,971 & 1.29 & 468 \\
\hline 19 & Air conditionir:g & 356 & 1,627 & 8.81 & 668 \\
\hline 20 & $\begin{array}{l}\text { Lighting and other } \\
\text { electric power }\end{array}$ & 835 & 1,535 & 3.44 & 268 \\
\hline & TOTA二 & 9,950 & 14,621 & & \\
\hline
\end{tabular}

Source: Reference 16). 
is estimated to grow at $2.2 \%$ per year between 1967 and 1985 , two-thirds that of the estimated 3.3\% annual growth in GNP between 1967 and 1985 .

Before the recent large increase in energy prices, both Almon (11) and BLS (12) estimated that the final demand for energy fuels (excluding imports, exports, and inventory change) in terms of constant dollars would grow at about the same rate as GNP, as compared to our estimate of energy products, in BTU's, growing at two-thirds the GNP rate. However, there is an estimated change in the mix of product BTU's toward a greater percentage of more fuel intensive air conditioning and electric power BTU's in 1985, so that the amount of fuel inputs required to provide the product BTU's grow slightly more rapidly than the product BTU's. The aggregate demand growth rate estimated here is still lower than the equivalent Almon or BLS rates, however.

Energy Supply Final Demands

For the export, import, and inventory change final demand sectors, energy transactions are defined in terms of fuel categories rather than products. All inventory change and export estimates were taken from (6), as were import estimates for each energy supply sector except for crude oil and refined oil products. The latter estimates were obtained from model solutions, under the assumption that imported oil would be freely available at $\$ 9.00$ (1974\$). Estimated 1985 final demands (equal to exports and increases in inventory holdings less imports), are listed in Table IV.3 for each of the 12 energy supply sectors along with 1967 final demands and average annual 1967 to 1985 growth rates. Relative to 1967 dulluulls, largc inoreases are projected for crude oil, refined oil, and llalural gas imports and smaller increases for coal exports. 
Table IV. 3

Final Demands for Energy Supplies, 1967 and 1985

(positive values are net exports, negative values, net imports)

\begin{tabular}{|c|c|c|c|c|c|}
\hline $\begin{array}{l}\text { BNL 110-Order } \\
\text { Sector Number } \\
\end{array}$ & Sector Name & & $\begin{array}{r}1967 \\
\left(10^{12} \mathrm{BTU}\right) \\
\end{array}$ & $\begin{array}{c}1985 \\
\left(10^{12} \mathrm{BTU}\right) \\
\end{array}$ & $\begin{array}{c}\text { Average Annual } \\
\text { Growth Rate } \\
1967-1985 \\
(8 / y r) \\
\end{array}$ \\
\hline $1:$ & Coal & & 1,794 & 2,419 & 1.67 \\
\hline 2 & Crude oil \& gas & & $-2,074$ & $-9,306$ & 8.70 \\
\hline 3 & Shale oil & . & 0 & 0 & - \\
\hline 4 & Methane from coal & & 0 & 0 & -- \\
\hline 5 & Solvent refined coal & & 0 & 0 & -- \\
\hline 6 & Refined oil products & . & $-2,158$ & $-11,521$ & 9.75 \\
\hline 7 & Pipeline gas & & -309 & $-5,692$ & 17.57 \\
\hline 8 & $\begin{array}{l}\text { Coal combined } \\
\text { cycle electric }\end{array}$ & & 0 & 0 & -- \\
\hline 9 & $\begin{array}{l}\text { Other fossil } \\
\text { electric }\end{array}$ & & & & \\
\hline 10 & LWR electric & & & & \\
\hline 11 & HTGR electric & & 1 & -8 & -- \\
\hline 12 & Hydroelectric & & & & \\
\hline
\end{tabular}

Sources: - Reference (6), except for 1985 import amounts for gas, crude oil and refined oil sectors. These amounts are model solution values. 
Interindustry Energy Product Coefficients

Values of the $A_{p s}$ and $A_{p m}$ energy product coefficients were obtained from (6). Values of the input coefficients into the energy supply sectors -- coal (1), crude oil and gas (2), petroleum refining (6), gas utility (7), fossil electric (9) and hydro-electric (12) -- are based on Bureau of Economic Analysis (BEA) estimates for 1967 (13), and are assumed to remain constant at 1967 values. The input coefficients for coal, crude oil and petroleum products are probably increasing over time due to product-mix changes toward higher quality products required by environmental regulations and also because of the depletion of the more accessible primary resource deposits, and the consequent need for increasingly expensive extraction techniques. These tendencies toward greater input requirements may be offset, however, by technological efficiency improvements. Environmental regulations have also been increasing input requirements for the electricity sectors, offsetting technological improvements. Estimates of input coefficients for the relatively new energy supply sectors $3,4,5,8,10$, and 11 are based on detailed engineering studies obtained from (14) and relate to expected 1985 conditions rather than past historical estimates.

The input coefficients for energy products to non-energy sectors are assumed to remain constant between 1967 and 1985 at 1967 values. Little direct evidence is available to test this assumption due to the paucity of data concerning end uses of energy. However, indirect evidence based on studies of fuel trends in selected energy-intensive processes and industries suggest that, on balance, the product coefficients are probably decreasing over time, though with considerable variation in rates among industries. A second trend which is reasonably evident, and which probably exists with almost all of the industrial and 
commercial purchasers, is a much slower decline in the per unit of output use of the electric power (lighting and electric drive) and air conditioning energy product categories. The first of these energy products, by definition, can only be supplied in the form of electricity and the second is supplied almost entirely by electricity.

Therefore, as a result of using fixed $A_{\mathrm{pm}}$ coefficients, the interindustry demands for energy products obtained from the combined model solutions should be considered as maximum amounts, and the degree of electrification indicated should be considered to be somewhat understated. Interindustry Coefficients, Excluding Energy

The $A_{\text {mm }}$ coefficients, also documented in (6), are based on expected 1985 conditions as estimated by BLS (12). Since the coefficients were estimated prior to the rise in energy prices brought on by the energy crisis, they may over estimate the use of such energy-intensive inputs as plastics.

All of the above five sets of parameters were inserted in the I-O model. Two further sets were required for the LP model.

\section{Linear Programing Model Parameters}

Estimation of projected future values of the $c_{j}, e_{y j}, d_{u j}, f_{w j}$, and $q_{y j}$ coefficients is an ongoing activity of the Energy Technology Assessment Group (ETAG) of Brookhaven National Laboratory. All values of these coefficients for 1985 were obtained from ETAG and are contained in Appendix B.

The results of the study are most sensitive to the capital and fuel costs associated with production of electricity via LWR's, coal steam electric plants, and oil steam electric plants. In 1985, it was assumed that capital costs, in constant $1974 \$$ per kilowatt, would be as follows: 
- Light-water reactors - $\$ 520 / \mathrm{kW}(e)$

- Coal-fired steam electric - \$425/kW(e)

- Oil-fired steam electric - $\$ 280 / \mathrm{kW}(e)$

The following 1985 fuel costs were assumed (in constant 1974 \$L:

- Fabricated uranium - $\$ .30 / 10^{6}$ BTU(t)

- Coal - $\$ 15.45 /$ ton at the mine mouth

- Residual fuel oil - $\$ 9.00 /$ barrel at the refinery.

Recently, in conjunction with other Brookhaven studies, most of these cost estimates have been increased. However, little change has been made in relative costs of nuclear versus non-nuclear fuel and capacities. 
:

THIS PAGE

WAS INTENTIONALLY

LEFT BLANK 


\section{Energy Supplies and Conversion Capacities}

The 1985 Base Case primary energy supply, electricity, and fossil fuel conversion estimates are listed in column (1) of Table V.1. Given all the parameter values presented in Chapter IV and open-ended availabilities, solution of the combined model yielded 14.6 quads of coal, 22.97 quads of imported oil, 3.00 quads of imported liquified natural gas, an amount of coal steam electric capacity sufficient to process 7.25 quads of coai, and a total primary energy resource input of 102.87 quads. For all other primary inputs and conversion capacities, maximum available amounts were prespecified, and all these amounts were utilized in the model solution, except for shale oil. For shale oil, it was assumed that government subsidies will be forthcoming by an amount sufficient to insure usage of .50 quads in 1985.

For purposes of comparison, two recent alternative sets of 1985 energy projections are listed in columns (2) and (3); the ERDA-48 Case 0 no new initiatives set of projections are listed in column (2), the FEA $\$ 13$ per barrel of imported oil projections are listed in column (3). With two major interrelated exceptions, the $\mathrm{BNL}$ estimates tend to be median estimates. The two exceptions are the low BNL estimates of the aggregate amount of electrification and the amount of domestic coal production.

Estimated average annual growth rates in domestic U.S. production between 1967 and 1974, and 1974 and 1985 for fossil fuels and electricity are listed in Table V.2. Between 1974 and 1985, domeslic coal and oil production both increase at a slow rate, while the production of natural gas declines. Elec- 
Table V.1

1985 Base Case Amounts of Energy Supplies and Conversion Capacities

(All Units in Quads $=10^{15}$ BTUs)

\begin{tabular}{|c|c|c|c|}
\hline & $\begin{array}{c}\text { BNL } \\
1985 \\
\text { Base Case } \\
\text { (Quads) } \\
\end{array}$ & $\begin{array}{c}\text { Used for } \\
1985 \text { ERDA-48 } \\
\text { Case } 0 \\
\text { (Quads) } \\
\end{array}$ & $\begin{array}{c}\text { Used for FEA } 1985 \\
\text { Reference Case } \\
\$ 13 / \mathrm{Bbl} \text {. } \\
\text { Imported Oil } \\
\text { (quads) }\end{array}$ \\
\hline \multicolumn{4}{|l|}{ Primary Resource Inputs } \\
\hline $\operatorname{Coal*}$ & 14.60 & 19.64 & 20.54 \\
\hline Domestic oil & 24.10 & 21.20 & 2.9 .05 \\
\hline Imported oil* & 22.97 & 25.94 & 12.12 \\
\hline Oil shale & .50 & 0.00 & 0.10 \\
\hline Domestic natural gas & 23.50 & 23.50 & 23.10 \\
\hline Imported natural gas* & 3.00 & .50 & 1.34 \\
\hline Total fossil & 88.67 & 90.78 & 86.16 \\
\hline \multicolumn{4}{|l|}{$\begin{array}{l}\text { Non-fossil to Electric } \\
\text { (LWR, HTGR, Hydruelectric, } \\
\text { Geothermal, Solar, and }\end{array}$} \\
\hline Total Energy Systems) & 14.20 & 15.00 & 12.61 \\
\hline Non-fossil direct (Solar) & 0.00 & 0.00 & 0.10 \\
\hline Total & 102.87 & 105.78 & 98.87 \\
\hline \multicolumn{4}{|l|}{ Electric Capacities (Inputs) } \\
\hline Coal steam* & 7.25 & 12.90 & 15.38 \\
\hline Oil steam & 2.73 & 3.00 & 1.40 \\
\hline Gas steam & 3.40 & 4.49 & 3.05 \\
\hline Gas turbine &. .7 & .7 .3 & 1.30 \\
\hline LWR. & 9.92 & 10.61 & 0.67 \\
\hline HTGR & .21 & .24 & 0.00 \\
\hline Hydroelectric & 3.38 & 3.38 & 3.38 \\
\hline Geothermal & .69 & .69 & 0.56 \\
\hline Solar & 0.00 & 0.00 & 0.00 \\
\hline Total electric inputs & 28.25 & 36.04 & 33.74 \\
\hline \multicolumn{4}{|l|}{$\begin{array}{l}\text { rossil Fuol Snnversion } \\
\text { Capacities (Inputs) }\end{array}$} \\
\hline Coal liquefaction & 0.00 & 0.00 & 0.00 \\
\hline Coal gasification & 0.71 & 0.00 & 0.10 \\
\hline Total fossil conversion & 0.71 & 0.00 & 0.10 \\
\hline
\end{tabular}


Table V.2

Domestic Energy Production, 1967 to 1985

Average Annual Growth Rates of Domestic Fuel and

Electricity Production

\begin{tabular}{|c|c|c|c|c|}
\hline & $\begin{array}{l}\text { BNL } 110 \\
\text { Sector No. }\end{array}$ & $1967-1974$ & $1974-1985$ & $1967-1985$ \\
\hline 1 & Coal & $1.0 \%$ & $.7 \%$ & $.8 \%$ \\
\hline 2,3 & $\begin{array}{l}\text { Crude oil, Crude } \\
\text { Gas, and Shale } \\
\text { Oil }\end{array}$ & .48 & $1.0 \%$ & $.8 \%$ \\
\hline 4,7 & $\begin{array}{l}\text { Refined Pipeline } \\
\text { and Coal Gas }\end{array}$ & $2.5 \%$ & -.38 & $.7 \%$ \\
\hline 6 & Refined Oil & 3.88 & .48 & $1.8 \%$ \\
\hline $8-12$ & Electricity & $5.5 \%$ & $4.2 \%$ & $4.7 \%$ \\
\hline
\end{tabular}

Source: 1967 and 1985 combined model solution vectors for outputs. 1974 production totals based on 1967 totals and 1967-1974 rates of increase estimated from the survey of Current Business, Department of Commerce, various issues. 
tricity production increases at just about the same rate as GNP, a rate which is much below recent historical rates.

\section{Energy Demands}

Average annual 1967 to 1985 growth rates of energy consumption activities are listed in column (3) of Table v.3. Air conditioning grows the most rapidly, ore reduction feedstocks the slowest. For most end use categories, final demand consumption, listed in column (2), grows less rapidly than inter-industry consumption, listed in column (1). However, Lhis differential in growth rates may be due to the assumed constancy in inter-industry energy product coefficients. As discussed earlier, this assumption may be suspect and would tend to overstate energy usage.

Given the assumed constant energy product coefficients, differentials in inter-industry usage growth rates by energy category are due to changes in the composition of the goods and services included in GNP. Coke usage grows more. slowly than GNP, as aluminum and plastics are substituted for iron and steel. On the other hand, air conditioning grows more rapidly than GNP as relatively more services are produced, and service industries tend to require relatively more air conditioning per unit of output.

While most energy demands grow more slowly than GNP, the rate of growth of aggregate energy demand still exceeds that of domestic fossil fuel production as both nuclear production and fossil fuel imports increase in relative and absolute importance. To the extent that increases in industrial energy efficiency decrease energy product coefficients below projected 1985 est1mates, the total 1985 domestic primary energy supply requirement may be less than the estimater 1.02 .87 guads. 
Table V.3

Domestic Energy Consumption, 1967 to 1985

Growth Rates of Energy Consumption Uses

by Type of End Use

1967-1985

BNL 110

Sector Number

13 Ore Reduction Feedstocks

14 Chemical Feedstocks

15 Motive Power

16 Process Heat

17 Water Heat

18 Space Heat

19 Air Conditioning

20 Lighting \& Other

Electric Power

Total Non-Energy Sectors

$\begin{array}{clll}\text { Inter- } & \text { Final } & \text { Total } & \text { Final Demand as } \\ \text { Industry } & \text { Demand } & \text { Usage } & \text { Percent of Total } \\ (z / \mathrm{yr}) & (z / \mathrm{yr}) & (\mathrm{z} / \mathrm{yr}) & \text { Consumption, } 1985\end{array}$

$---$

1.5

0. 8

3.7

2.4

3.7

2.48

4.2

2.0

2.9

57.88

3.4

1.5

3.3

$3.8 \%$

3.6

1.8

2.5

57.78

3.7

1.3

2.5

46.08

4.4

8.4

7.0

$65.8 \%$

3.9

3.4

3.8

26.48

3.6

3.3

3.5

48.28

Source: Model results. 


\section{Non-Energy Sector Gross Outputs}

The growth rates of the gross outputs of the 90 non-energy industries are listed in rank order in Table V.4. The dispersion in these growth rates is quite sizeable as some sectors increase in relative importance, others decrease. The cause of these relative changes are many -- changes in tastes and preferences, in technology, and in foreign trade patterns being the most important.

Differentials in non-energy sectoral growth rates of output, in turn, determine differentials in the growth rates of energy usage already considered. The causation is particularly clear in cases where energy resources are used as a feedstock. Coke usage grows at about the same rate as iron and steel production (slowly), while, petrochemical feedstock usage grows at about the same rate as plastics and plastic products (rapidly).

In order to determine the impact of nuclear moratorium legislation on these Base Case projections, we will next consider how possible nuclear legislation might affect the amount of nuclear capacity available in 1985. Then the impact of altered nuclear capacity availability amounts on these Base Case projections will be presented and analyzed. 
Table V.4

Average Annual Growth Rate of Domestic Output for Non-Energy Industries

1967-1985

BNL

$\underline{110}$

34

Industry

Maintenance and repair construction, residential Air transportation

Plastics and synthetic materials Service industry machines

Office, computing and accounting machines

Optical, opthalmic, \& photographic equip. \& supp. Rubber and miscellaneous plastics products Nonferrous metal ores mining Communications except radio \& television broadcasting Electronic components and accessories Engines and turbines Drugs, clcaning and toilet preparations Chemicals and fertilizer mineral mining Chemicals and selected chemical products Other transportation equipment Electric lighting and wiring equipment. Miscellaneous elec. machinery, equipment \& supplies Federal government enterprises

Elec. trans. \& dist. eq. \& elec. industry apparatus Miscellaneous textile goods and floor coverings Motor vehicles and equipment New construction, public utilities Medical, educ. services \& nonprofit inst. Pximary nonferrous metals manufacturing Household appliances Miscellaneous fabricated textile products Paints and allied products Radio, television and communications equipment Forestry and fishery products

Business services Paving mixtures and blocks Materials handling machinery and equipment Finance and insurance

General industrial machinery and equipment Hydroelectric

Asphalt felts and coatings Wholesale and retail trade Metal containers Paper and allied products except containers and boxes Professional, scientific and controlling inst. and supp.
Growth

Rate \& Per Year

8.01

7.84

7.53

6.90

6.85

6.75

6.56

6.46

6.16

5.97

5.88

5.59

5.44

5.40

5.20

5.13

4.86

4.71

4.68

4.63

4.62

4.59

4.55

4.53

4.50

4. 32

4. 32

4. 30

4.29

4,25

4.22

4.14

4.03

3.98

3.90

3.85

3. 79

3.79

3.79

3.79 
Table V.4 (cont'd)

BNL

110

66

88

64

48

108

101

41

91

43

69

109

59

29

74

49

45

104

27

39

37

60

21

98

46

22

1.05

102

94

71

25

9

72

35

110

6

30

61

84

38

95

65

97

89

33
Industry

Other fabricated metal products

Miscellaneous manufacturing

Heating, plumbing and fabricated structural metal products

Paperboard containers and boxes

State and local government enterprises

Real estate and rental

Apparel

Motor freight transportation and warehousing

Lumber and wood products, except containcrs

Construction, mining, oil field machinery, equipment

Business travel, entertainment and gifts

Glass and glass products

New construction, residential buildings

Machine shop products

Printing and publishing

Household furniture

Automobile repair and services

Stone and clay mining and quarrying

Broad and narrow fabrics, yarn and thread mills

Food and kindred products

Stone and clay products

Livestock and livestock products

water and sanitary services

other furniture and fixtures

other agricultural products

Dmusements

Hotels \& lodging; pers. \& repair serv., except auto repair

Pipe line transportation

Metalworking machinery and equipment

Iron and ferroalloys ores mining

Other Fossil electric

Special industry machinery and equipment

Maintenance and repair construction, all other

Office supplies

Refined oil products

New construction, nonresidential buildings

Primary iron and steel manufacturing

Aircraft and parts

Tobacco manufactures

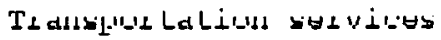

Screw machine prod., bolts, nuts, etc. and metal stampings

Radio and TV broadcasting

Railroads and related services

New construction, all other
Growth

Rate

응 Pear

3.70

3.68

3.68

3.47

3.44

3. 37

3.36

3.35

3. 33

3.31

3. 18

3.15

2.97

2.93

2.92

2.80

2.78

2.78 .

2.65

2.61

2.55

2.48

2.45

2. 34

2.30

2. 28

2. 24

2.26

2.13

2.12

2.03

1.99

1. 85

1.83

1.83

1. 71

1.42

1. 31

1. 19

1. 03

.93

.90

.84

.77 
Table V.4 (cont'd)

BNL

92 Water transportation \& Per Year

68 Farm machinery

44 Wooden containers

24 Agricultural, forestry and fishery services

5 Solvent refined coal

90 Local, suburban and interurban highway pass. trans.

.77

.68

.19

.14

0.0

$-.17$ New construction, highways

$-1.07$

Footwear and other leather products

$-1.14$

ordnance and accessories

$-1.45$

36
57

Leather tanning and industrial leather products

$-6.51$ 
THIS PAGE

WAS INTENTIONALLY

LEFT BLANK 
Chapter VI. Estimation of the Impact of Possible Nuclear

Moratorium Legislation on the 1985 Availability of Nuclear Electric Capacity

Introduction

Until the recent recession, the nuclear electric industry has experienced rapid rates of growth -- far more rapid than the electric utility industry as a whole, which, in turn, has grown faster than GNP. Several factors account for this increasing role of nuclear power in generating electricity. Among others, these include:

-government sponsored research, development and demonstration of nuclear technology, which has lowered capital costs and increased operating efficiency and safcty;

-restrictions on the use of high sulfur content coal and residual fuel oil due to the imposition of environmental regulations on electric utilities; - sharp increases in the price of residual fuel oil and growing uncertainty as to its future availability arising from the behavior of the OPEC cartel.

However, despite all these factors favorable to the further development of the nuclear electric industry, including the continuing promotion of the nuclear industry by the Federal government, the future competitive position of nuclear power as an alternative to coal, oil, or gas in the production of electricity may still be in doubt. Unlike the past experience of most growth industries in their early stages of development, recently the costs per unit of nuclear generated electricity output have been increasing rapidly, both in nominal and real terms. These cost increases have resulted from a number of interrelated economic factors affecting the cost of constructing and operating nuclear facilities. They include increasingly stringent and costly environmental 
and safety regulations, lengthening of planning and construction time lags, increases in interest rates, increases in the cost of future uranium supply contracts, and continuing unforeseen technical construction problems. The operating rates of existing nuclear facilities have alșo been disappointing, as unexpected technical operating problems and the imposition of retroactive safety requirements have increased the down time of nuclear plants.

Nuclear plants have also come under sharp attack for less strictly economic reasons -- that they impose intolerable safety and environmental risks on society, or alternatively, that the degree of centralization and safeguard precautions required to limit security risks may in turn require intolerable restrictions on civil liberties.

All these factors, plus the recent decline in the demand for electricity caused by higher electricity prices and reduced levels of industrial output have led several utilities to cancel or delay previously planned nuclear construction programs. In addition, environmental groups are currently advocating state and federal legislation to further delay or cancel nuclear electric activities. The most ambitious attempt in this direction was the heavily promoted moratorium referendum in California. Despite the defeat of this referendum, the future of the nuclear industry may no longer be as predictable as it once seemed.

All of the above factors currently restricting the future growth of the industry may well be one-shot problems which will be quickly and readily resolved; and, once resolved, accumulated learning experience together with further technical improvements in construction and operation, may lower nuclear costs along the cost path usually associated with newly emerging growth industries. These are the assumptions which have led most utilities to choose nuclear power as their primary energy source for generating electricity in the years to 
come. Coal, is the only other near term energy source seriously being considered for base-loaded plants, particularly for plants with ready access to coal deposits. However, the near term future of coal, too, is uncertain, as it hinges on future environmental regulations and/or improved technology for removal of sulfur compounds either from the coal or from the combustion products of coal, as well as the development of an improved transportation network to transport the coal.

Estimation of the Base Case Amount of Nuclear Electric Capacity

As of December 31, 1974 utilities estimated their on-line nuclear capacity would be 199 gigawatts $\left(10^{9}\right.$ net $\left.\mathrm{kw}(e)\right)$ in 1985. In the Base Case this projection was lowered some $13 \%$ to 174 gigawatts on the basis of assumed further delays or cancellations in utility planning and construction timing estimates. Since currently there exists an estimated 12 year average lead time between conception and start-up operation. Unless this lead time is cut sharply, few plants not included in the utilities' December 13, 1974 estimates will be on-line by 1985. Thus the Base Case 174 gigawatt capacity estimate is near the upper limit of maximum possible 1985 capacity.

In the BESOM model, nuclear LWR and HTGR capacities are defined in terms of annual quads $\left(10^{15} \mathrm{Btu}\right.$ 's) of uranium input processed. In converting capacity estimates from gigawatts to quads, the following plant operating rates and fuel efficiencies were assumed for LWR's and HTGR's in 1985:

\section{Operating Rate (Amount of Use Time Per Amount of Available Time)}

198b Efficiency (BTU of Electricity Uutput Fer BTU of Heat Input)
LWR

HTGR
.65

.65
.33

.40 
Under all cases analyzed, it was assumed that small amounts of HTGR capacities would be available by 1985. Recent events cast doubt on this assumption, however, so that HTGR capacities should be interpreted as LWR capacities. Estimation of Alternative 1985 Amounts of Nuclear Electric Capacity

Four alternative estimates to the Base Case estimate of 174 gigawatts are listed on Table V.l. These estimates were projected on the basis of the following possible policies occurring in early 1976.

1) "Moratorium" - A Twh-Year Moratorium Is Impoed on All Future Nuelear. Plans, and Construction Activities in 1976. The moratorium is followed by a delayed continuation of expected utility nuclear construction trends. It was assumed that the impact of such legislation would be to cause a three year delay in the planned completion date of plants already under construction, and a four year delay in starting construction of plants currently planned.. Delays in construction and planning would be greater than the official length of the moratorium itself on account of both increased supply shortage bottlenecks occurring right after the cessation of the moratorium, and because of the uncertainty generated by the moratorium. The impact of these delays would he to derrease the eventual 1985 capacity by $40 \%$

2) "No-New": A Permanent Ban on All New Construction After January 1,

1977. This policy would reduce the 1985 Base Case capacity estimate by $43.8 \%$. 3) "Old Only": A Permanent Ban on All Plants Not Finished by January 1, 1977. This policy would reduce the 1985 Base Case raparity by 79.2\%: 4) "Total Ban": A Ban on All Existing and New Nuclear Operation. This policy would eliminate the industry.

other things remaining equal, policies requiring greater reductions in nuclear capacity will have greater impacts on the economy. However, several 
Table VI.I

1985 LWR and HTGR Nuclear Electric Capacity

Amounts, by Type of Nuclear Policy

LWR PIUS HTGR Capacity

\begin{tabular}{|c|c|c|}
\hline Policy Assumption & $\begin{array}{c}\text { (Gigawatts of } \\
\text { Electricity) } \\
\end{array}$ & (Quads of Inputs) \\
\hline Base Case & 174.2 & 10.13 \\
\hline Moratorium & 104.5 & 6.09 \\
\hline No-New & 97.6 & 5.69 \\
\hline old-only & 36.1 & 2.09 \\
\hline Total Ban & 0.0 & 0.0 \\
\hline$\star$ & & \\
\hline Source: see text. & & \\
\hline
\end{tabular}

factors besides the size of the nuclear cutback will influence the impact of moratorium policies. Some of these factors are considered in the next chapter. 
THIS PAGE

\section{WAS INTENTIONALLY \\ LEFT BLANK}


Chapter VII. Specification of Possible Responses to Decreases

in the 1985 Base Case Amount of Nuclear Electric Capacity

\section{Introduction}

The impact of a cutback in nuclear capacity on the state of the 1985 economy will obviously depend on the size of the cutback and the anticipated level of economic activity. However, several other factors besides the size of the cutback will influence the nature and severity of its effects -- in particular:

1) The degree to which available non-nuclear generating capacity can be used more intensively in 1985;

2) the degree to which greater amounts of fossil fuels and generating capacities can be made available to offset the decline in nuclear electric capacity;

3) the degree to which other fuels can be substituted for electricity in providing energy for heat, light, power, and feed-stock requirements; and

4) the degree to which the demand for energy can be reduced voluntarily via increases in the fuel efficiency of energy using end use devices, and/or decreases in the consumption of end use heating, lighting, power, or feedstock activities.

The actual magnitude of these responses will be dependent both on the lead time that consumers, business firms, and utilities have to adapt to the cutback, and on the nature of the government policies directed to stimulate or retard these response mechanisms. The longer the period energy purchasers have to anticipate nuclear cutbacks, the less energy consumption of households and businesses will have to be reduced involuntarily via forced rationing of electricity and/or large price increases. In the analysis to follow, four possible response cases are considered -- two on the supply side and two on the demand 
side. The first three mechanisms would operate over the 1976 to 1985 period, the last only in 1985.

Response Cases Considered

Response Case 1 - Coal and Coal Steam Electric Response - In this case, the 1985 Base Case LWR and HTGR availabilities were decreased by amounts corresponding to the four nuclear reductions, while the availability of coal and coal steam electric capacity were unconstrained. Using Base Case values for all other IO-LP model parameters, the model was solved for the magnitude of endogenous variables, which were then compared with Base Case values.

Response Case 2 - Oil and Oil Steam Electric - In this case, the same methodology was followed as in the Coal Response Case, except that imported oil and oil steam electric capacity were unconstrained and the availabilities of coal and coal steam electric generating capacity were kept constant at Base Case levels.

For each of these supply response cases, changes in. Givf were estimated under the assumption that the aggregate amount of employmene in 1985 would remain constant at the Base Case level. Several additional supply response cases could have been run by allowing other types of electricity capacity to vary, e.g., gas steam electric and hydro capacity, and base loaded gas turbine capacity. These alternatives were ruled out a priori. Given expected future fuel and capital costs, they will clearly be more expensive than the two alternatives considered.

In addition to the two supply cases, one intermediate term demand case was considered.

Response Case 3 - Conservation - This case finds the amount by which the efficiency of energy use by households and businesses would have to increase in 
order to keep GNP and employment constant, assuming Base Case availability amounts of all non-nuclear energy supplies and conversion capacities. Given LWR and HTGR availability corresponding to each nuclear policy, along with other 1985 Base Case fuel supply and capacity amounts, the IO-LP model was solved to find that uniform percentage decrease in all energy product requirements, spread uniformly across all interindustry and fuel demand uses, which would be required to maintain the Base Case level of aggregate final demand, (net of energy). The solution values of all the exogenous model variables were then compared with the Base Case model estimates.

Consideration of the technological and economic mechanisms which would be required to bring about decreases in energy demand are not included in the model structure itself. Both energy RD\&D to improve efficiency of end-use devices and price-induced voluntary substitution of capital intensive energy saving end-use devices for more energy intensive devices would decrease energy requirements. These mechanisms, in turn, would also change the structure of non-energy technology embodied in the input-output coefficients, and the level and structure of the investment vector. These second-order effects are not estimated. This is an area that needs considerable additional research.

Response Case 4-Curtailment - Since neither alternative energy supplies nor more energy efficient energy using technology can be installed instantaneously, solutions corresponding to each of the above response cases will be feasible only if sufficient time exists to implement the required alternatives. Should little or no advance notice be given of any nuclear cutback, there would cxist little time for increasing the availability of other energy capacities and/or adopting more energy efficient using devices. This situation might arise from a sudden shut down of nuclear capacity following some nuclear-related 
accident. Given such an event, declines in nuclear capacity would lead to almost proportional declines in electricity consumption, since only minimal amounts of electricity can be imported or stored in batteries. However, the availability of any non-nuclear standby capacity and fuel inventories would permit some compensating increase in electricity production, as would increases in the operating rates of non-nuclear electric capacities.

Two versions of this curtailment case were analyzed. First, it was assumed that all businesses and consumers would be forced to cut back their purchases of electricity by the same percentage as the decline in aggregate electricity production, the size of the cutback being determined by the size of the nuclear cutback. The input-output model was then used to estimate the percentage decline in GNP and employment resulting from each nuclear cutback. Next, provision was made for the existence of some stand-by gas turbine capacity in 1985 and for limited substitution of oil, coal and gas for electricity in meeting space, water, and process heat demands. The combined IO-LP model was then used to estimate the resulting decline in GNP, outputs, and employment associated w1th each nucled culitack. 


\section{Chapter VIII. Presentation and Analysis of Model Results}

\section{Coal Response Case}

In this response case, the values of all exogenous variables are kept constant at Base Case amounts except for the following variables. LWR and HTGR nuclear capacity amounts are decreased to amounts corresponding to the particular nuclear policies discussed in Chapter VI, while the availabilities of both coal and coal steam electric capacity are kept unlimited. That is, in this case it is assumed that unlimited amounts of coal and coal capacity at constant costs will be available in 1985 as potential substitutes for uranium and nuclear capacity. The amounts of coal and coal steam electricity capacity which would actually be required to compensate for the decrease in nuclear capacity are then estimated by the combined model, along with all other endogenous variables.

Table VIII.l lists the amounts by which domestic coal production and coal steam electric capacity would have to increase to compensate for the given declines in nuclear capacities. For every 1 quad decrease in nuclear capacity, coal steam capacity and domestic coal. production would have to increase about 0.9 quads. The required rate of substitution of coal capacity for nuclear capacity is less than $1: 1$ for these three reasons:

1) the direct and indirect electricity requirements for providing coal and coal steam capacities are less than those for uranium and nuclear capacity;

2) as the price of electricity increases, less electricity is used in space heating and water heating. The pricc of electricity increases $13 \%$ for the old Only policy) since coal produced electricity is more expensive than nuclear produced electricity. 
Table VIII.I

Coal Response Case Model Results for Energy Sector Variables

CHANGES IN NUCLEAR CAPACITY, COAL STEAM ILECTRIC CAPACITY

AND DOMESTIC COAL PRODUCTION

ASSOCIATED WITH EACH NUCLEAR POLICY

Reduction From Base Case Amounts of LiR \& HTGR Capacities

Nuclear Policy
Moratorium
Old Only
Total Ban
Base Case Amounts

\section{Quads of Inputs}

4.04

4. 44

8.02

10.13

10.13
Increase From Base Case Amount Required to Minimize GNP Decrease

\section{Coal Stear Electric Capacity Domestic Coal Production}

\section{Percentage}

Reduction

$$
39.98
$$

43.38

79.28

100.08

3.70

4.06

7.24

9.05

7.25

Percentage Percentage

Increase Quads Increase

$51.0 \%$

3.70

25.38

$56.0 \%$

4.10

28.18

$99.8 \%$

7.20

49.38

124.88

9.00

61.68
14.60 
3) slightly greater amounts of electricity are produced from given amounts of coal steam capacity than from equivalent amounts of nuclear capacity being replaced. It is assumed that in 1985 the BTU input to BTU output efficiency ratio will equal 0.35 for coal steam electric capacity, 0.34 for LWR capacity, and 0.40 for HTGR capacity.*

Table VIII.2 lists the changes in GNP associated with decreases in nuclear capacity. GNP declines slightly as more labor, capital and material inputs are required directly and indirectly to produce electricity via coal than via nuclear. The GNP decreases are small, however, for all policies except the Total Ban policy. For the old Only nuclear policy, the aggregate minimized cost of energy increases by $0.8 \%$ over the Base Case cost. Energy costs in turn are only a small portion of total economy-wide input costs.

In estimating these 1985 GNP reductions, it is assumed that all labor, capital and material inputs required by the construction and operation of nuclear plants in the Base Case would be reallocated to other sectors as the 1985 availability of nuclear plants declined. However, resources currently embodied in the amount of nuclear capacity which is already in place as of 1976 could not in fact be reallocated. Thus for the Total Ban nuclear policy, model results had to be adjusted so as to allow for this non-allocation effect.

The investment component of GNP decreases sharply. This occurs as a result of the fact that coal electric capacity is less capital intensive than nuclear capacity. Capital requirements outside the energy sector remain at Base Case levels. Since less resources are required for provision of nuclear related eapital goods, mire dre available for the production of consumer goods and ser-

*This assumption varies from the U.S. Bureau of Mines accounting procedure which assigns a heat rate (and thus an efficiency) to nuclear plants equal to the average heat rate for fossil fired plants. 
Table VIII. 2

Coal Response Case Model Results--GNP Variables

Percent Changes in GNP and its Composition

Associated with each Nuclear Policy

Percentage Change from Base Case

\begin{tabular}{|c|c|c|c|c|c|}
\hline Nuclcar Policy & GNP & Snnsumption & $\begin{array}{c}\text { Energy } \\
\text { Inves tment } \\
\end{array}$ & $\begin{array}{l}\text { Non-Energy } \\
\text { Investment }\end{array}$ & $\begin{array}{c}\text { Total } \\
\text { Investment }\end{array}$ \\
\hline Moratorium & $-.006 \%$ & +0.98 & -13.38 & -0.28 & -4.38 \\
\hline No New & -.0078 & +1.08 & -21.28 & -0.28 & -4.78 \\
\hline old only & -.0188 & +1.78 & -36.48 & -0.38 & -8.18 \\
\hline Total Ban* & $-.035 \% *$ & $+2.08 *$ & $-41.48 *$ & $-0.48 *$ & $-9.28 *$ \\
\hline $\begin{array}{l}\text { Base Case Amour } \\
\text { (in Billions }\end{array}$ & & - & & & \\
\hline of $1967 \$)$ & $\$ 1439.0$ & $\$ 904.7$ & $\$ 41.5$ & $\$ 151.4$ & $\$ 192.9$ \\
\hline
\end{tabular}

*These estimates assume that resources presently embodied in existing nuclear plants could be reallocated to alternative uses. Allowance for waste of this resource increases the GNP reduction another .108 to .1358 . 
vices in 1985. After 1985, however, aggregate consumption would increase somewhat slower with coal-fired electricity plants than it would with nuclear plants, as the operating productivity of coal plants is less than that of nuclear plants.

Figure VIII.I shows the non-energy sectors with the largest percentage changes in gross outputs (relative to Base Case Amounts). In general, outputs of industries which are consumer oriented (such as food, tobacco, and apparel) increase while output of industries which are capital goods oriented (such as construction and farm machinery) decrease.

The changes in the outputs of sectors 28 (Chemicals and Fertilizer Mining) and 50 (Chemicals and Chemical Products) are directly related to the reduction in nuclear electricity. Sector 28 includes uranium mining, and sector 50 includes uranium enrichment and reprocessing activities, all of which decline with decreases in the amount of nuclear produced electricity.

The percentage increase in the output of the railroad industry is directly related to the increase in coal production. In fact, even greater railroad (or coal pipeline) production would be required than estimated here, since transportation requirements for coal shipments to fossil utilities are underestimated when only the coal portion of fossil utilities is increased. That is, greater model disaggregation would have yielded larqer railroad requirements. Changes in energy product consumption arising from the substitution of coal for nuclear electricity production are shown in Figure VIII.2. The consumeroriented uses of energy (e.g., private ground transportation) increase, while the industrial uses of energy (e.g., petrochemical feedstocks) decrease.

Figure VIII. 3 shows the sectors which would show the largest changes in employment. For a constant GNP, the coal response cases would lead to a slight increase in aggregate employment from the Base Case amount, since industries 


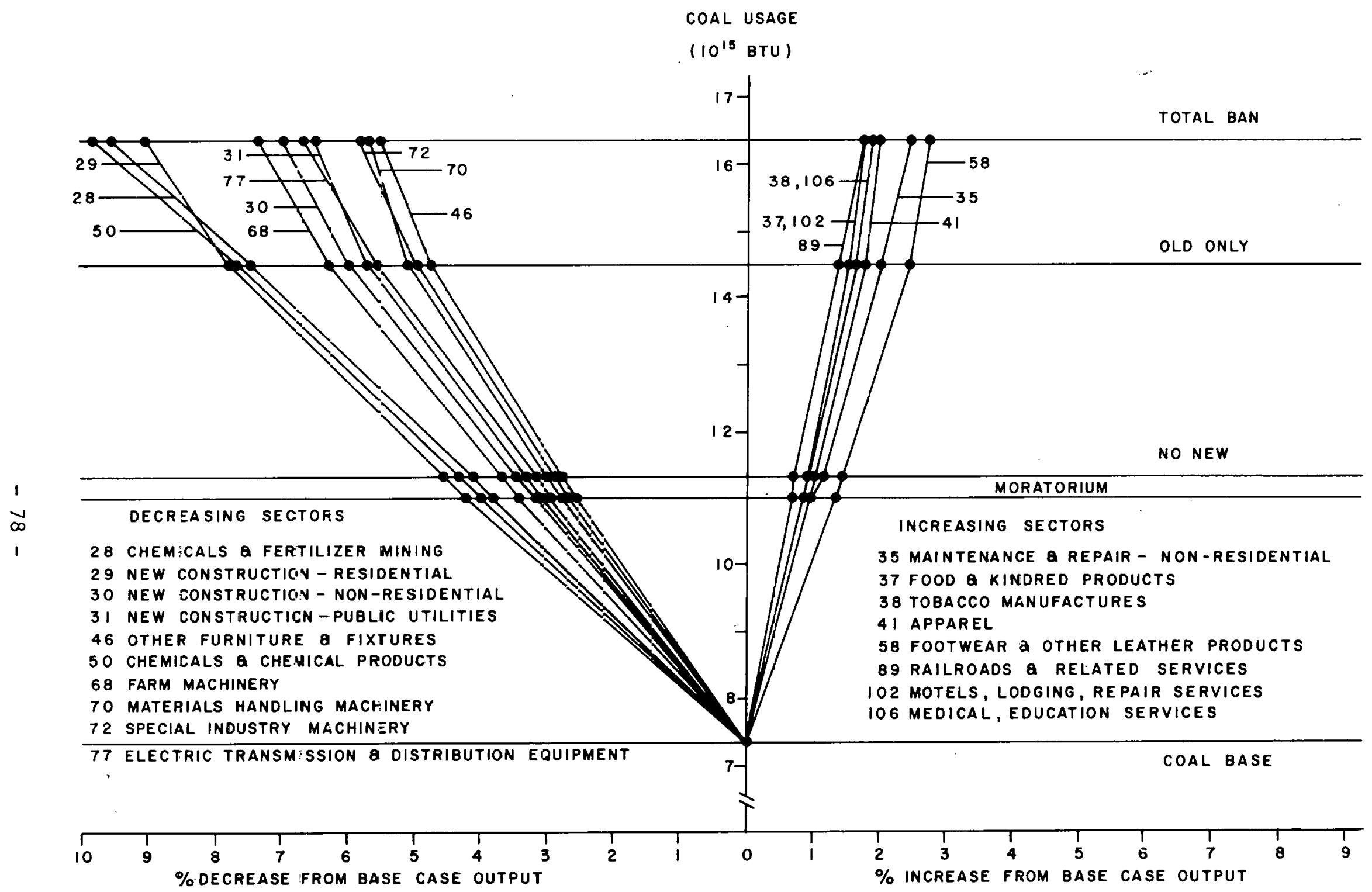

AL: NON-ENERGY OUTPUTS ARE MEASURED IN CONSTANT 1967 DOLLARS.

Figure VIII.1. Percent change in 1985

base case amounts of non-energy outputs

with coal response to nuclear policies. 


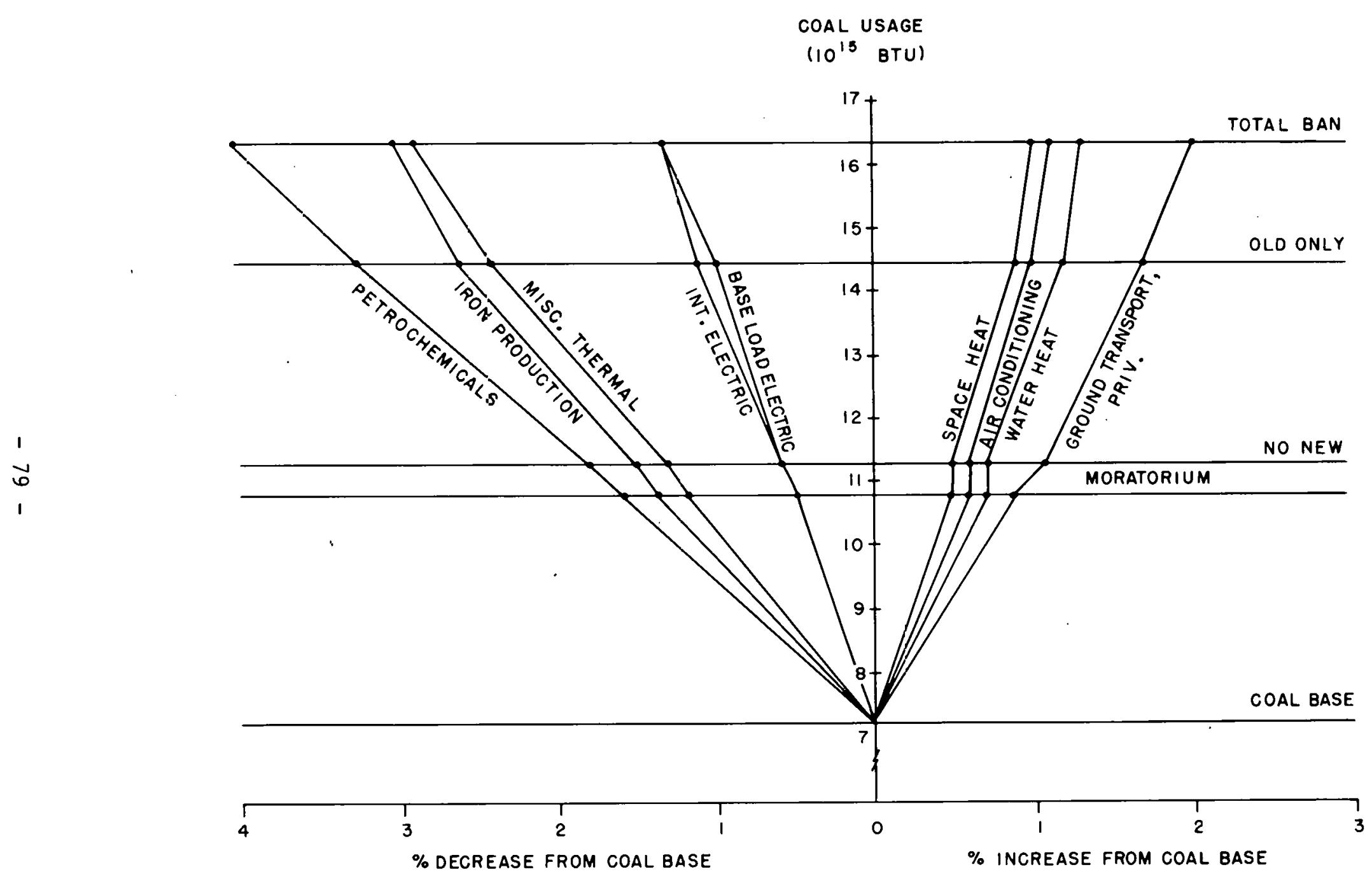

ALL ENERGY PRODUCT OLTPUTS ARE MEASURED IN UNITS OF $10^{15}$ BTU (BRITISH THERMAL UNITS)

Figure VIII.2. Percent change in 1985

base case amounts of energy product con-

sumption with coal response to nuclear

policies. 


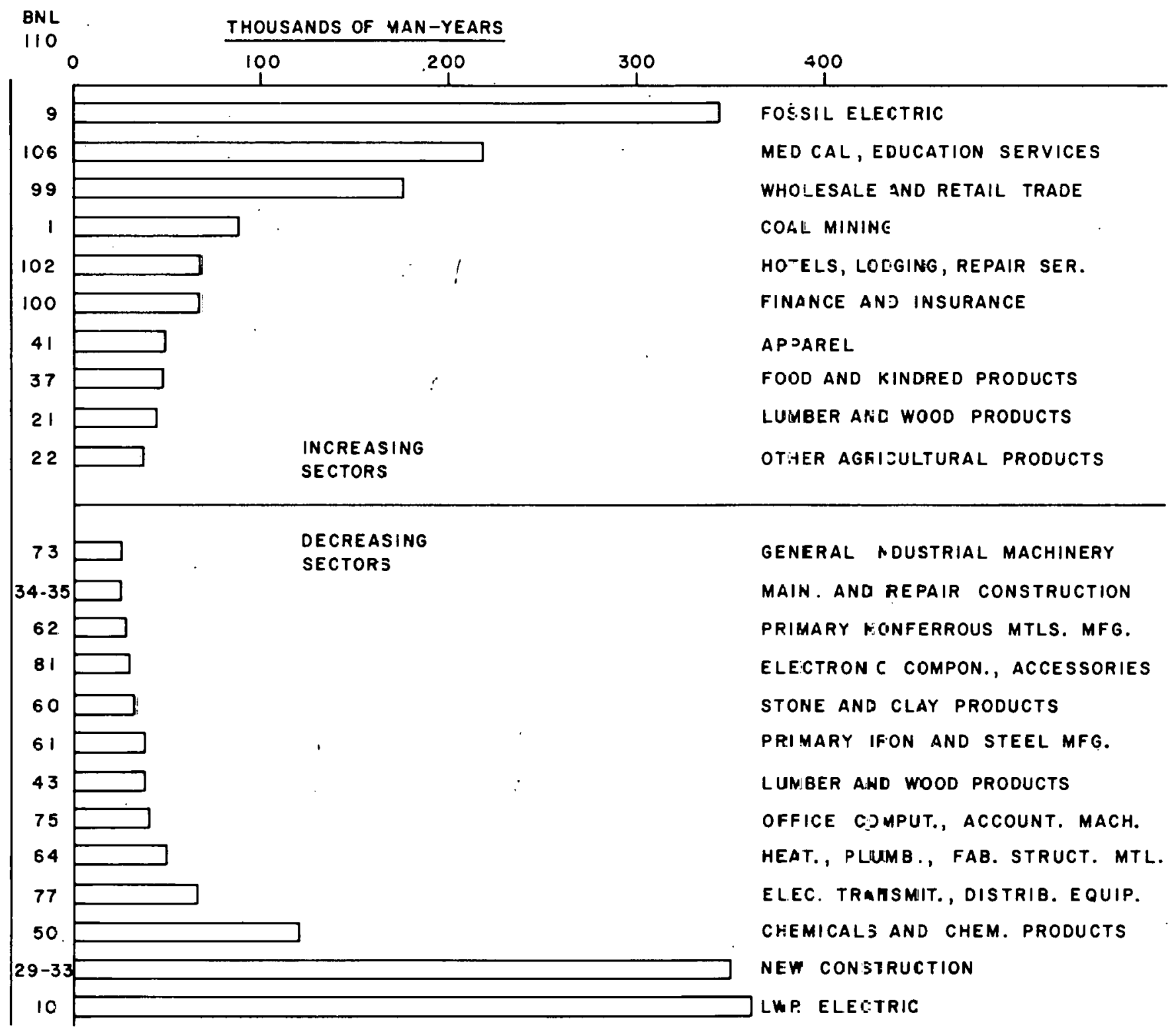

Fignre VIII.3. Change in 1985 base case

empioyment in selected industries with

coal response to total ban nuzlear policy. 
whose outputs expand tend to be more labor intensive than those which contract. This increase in aggregate labor requirements leads, in turn, to the decrease in GNP, assuming a constant unemployment rate.

\section{Imported Oil Response Case}

In this response case, values of all exogenous parameters were set at 1985 Base Case amounts, except for the following:

- LWR and HTGR capacities, which were decreased by amounts corresponding to the nuclear reduction policies described in Chapter VI.

- Oil imports, which were assumed to be available in infinite quantities at the Base Case price (\$9/barrel, 1974\$).

- Oil steam electric capacity, which was assumed to be available in 1985 at constant costs in amounts sufficient to offset the decline in LWR capacity.

In addition to changing 1985 availability estimates of the above variables in the linear programming model, the final demand sectors of the inputoutput model were also adjusted so that

- Aggregate labor employment remained at the Base Case level.

- Balance of payments equilibrium was achieved for any amount of oil imports.

For this response case, a balance of payments equilibrium mechanism was added to the input-output model as follows. For every dollar worth of oil impurts over the base case, it was assumed that net exports would increase by $60 \%$ and crcludcd model transactions by 404 . The excluded model transactions include capital flows and U.S. exports produced by U.S. firms located outside the U.S. For every dollar's worth of increase in net exports, aggregate consumption decreases by the same amount, thus freeing resources to expand export pro- 
duction. The sectoral composition of the increases in net exports was estimated from import and export price elasticity estimates obtained from (11).

Table VIII. 3 lists the amounts by which oil imports and oil steam electric capacities would have to increase to compensate for the decline in nuclear production. The required rate of substitution of oil imports (in quads) for uranium (in quads) is close to $1: 1$; however, it is less than $1: 1$ for oil electric capacity replacements of nuclear electric capacity, since aggregate electric capacity and production decline.

Aggregate electricity capacity requirements decline for the following reasons: 1) previously existing capacity (particularly gas turbine capacity). is used more intensively; and 2) the average price of electricity increases, leading to a decline in electricity consumption, particularly in space heating. In the old only Case, the average price of electricity increases $6 \%$ over the Base Case price.

Table VIII.4 lists the percentage change in GNP and its components which are associated with each decline in nuclear capacity. The percentage reductions in GNP Increase to $.031 \%$ fur llie old Only Casc, ne with the roal response case, the reductions for all policies except the Total Ban policy are small because the additional direct plus indirect labor and capital costs required in 1985 to replace nuclear facilities with oil and oil burning facilities are quite small. The GNP reduction exceeds that for the coal case because the dveldye aulial sogts of generating electricity via oil exceed that for cual. This reduction in CNP will continue beyond 1985 however, since, once in place, oil generating plants require more operating inputs, and thus indirectly, more capital and labor inputs than do nuclear plants. 
Table VIII. 3

Imported Oil Response Case Model Results--Energy Sector Variables

Changes in Nuclear Capacity, Oil steam Electric Capacity and Oil Imports Associated with Each Nuclear Policy

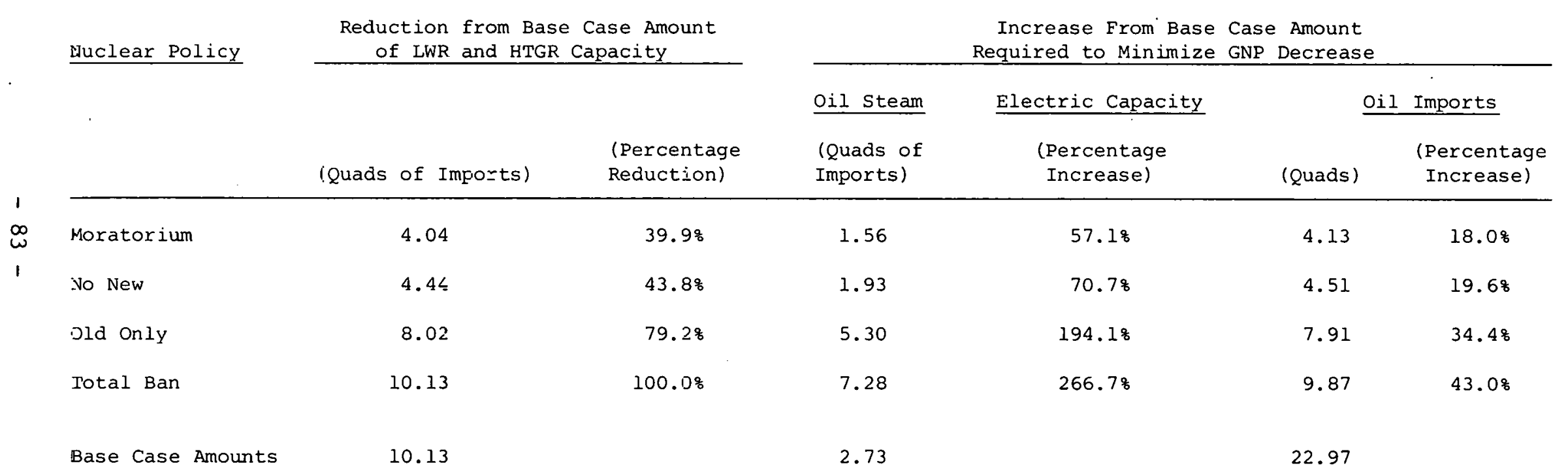

Source: Model results. 
Table VIII.4

Imported Oil Case--Model Results for GNP Variables

Percentage Changes in GNP and its Composition

Associated with Nuclear Policy

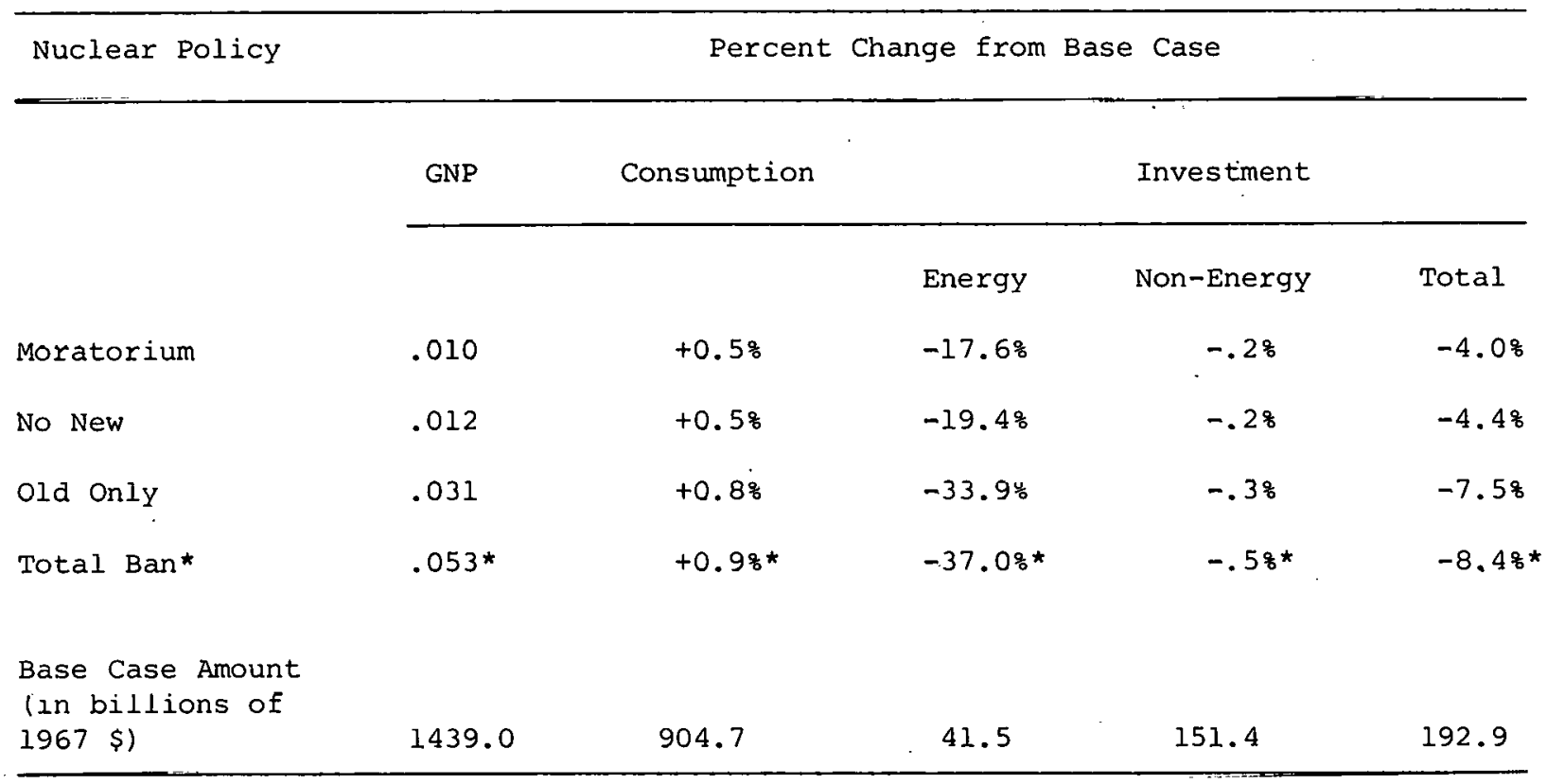

Source: Modol remilt.r:

*These estimates assume resources presently embodied in existing nuclear plants would be reallocated to alternative uses. Allowance for waste of these resources increases the GNP reduction another . $100 \%$ to .153\%. 
For the Total Ban nuclear policy, the GNP reduction increases to . $153 \%$, or $\$ 2.2$ billion in constant 1967 dollars. About two-thirds of this reduction is attributable to the waste of nuclear capacity already in place. Investment requirements for the energy sector decrease sharply in 1985 since less aggregate electricity capacity is required. In addition, oil plants also require less capital investment than equivalent sized nuclear plants. However, aggregate economy-wide investment declines less under oil response cases than under coal cases. This results from the fact that with additional oil imports, export requirements increase, and, on balance, export industries are capital intensive. In 1985, in the oil response cases, some net reallocation of resources toward greater production of consumer goods still occurs. In the Total Ban policy case, aggregate consumption increases $0.9 \%$ in 1985 , or $\$ 8.1$ billions in 1967 dollars. In future years, aggregate consumption would become smaller than otherwise, however, since the operating productivity of oil plants is less than that of nuclear plants.

Figure VIII.4 shows the percentage changes from Base Case amounts in the outputs of sectors undergoing the largest percentage changes. The chemical sectors, which include uranium mining and enrichment (28 and 50), decrease up to 9-10\% in the Total Ban Nuclear policy case, while investment-oriented sectors decrease by smaller amounts as a result of the decline in aggregate investment. Outputs of the water and pipeline transportation industries increase as a result of the additional oil imports. Outputs of consumer-oriented sectors increase by small percentages while outputs of those industries sensitive to foreign trade, such as the shoe and leather industry and the agricultural industry, also increase. Figure VIII.5 shows the sectors in which the largest absolute changes in employment would occur. These changes parallel the sectoral output changes 


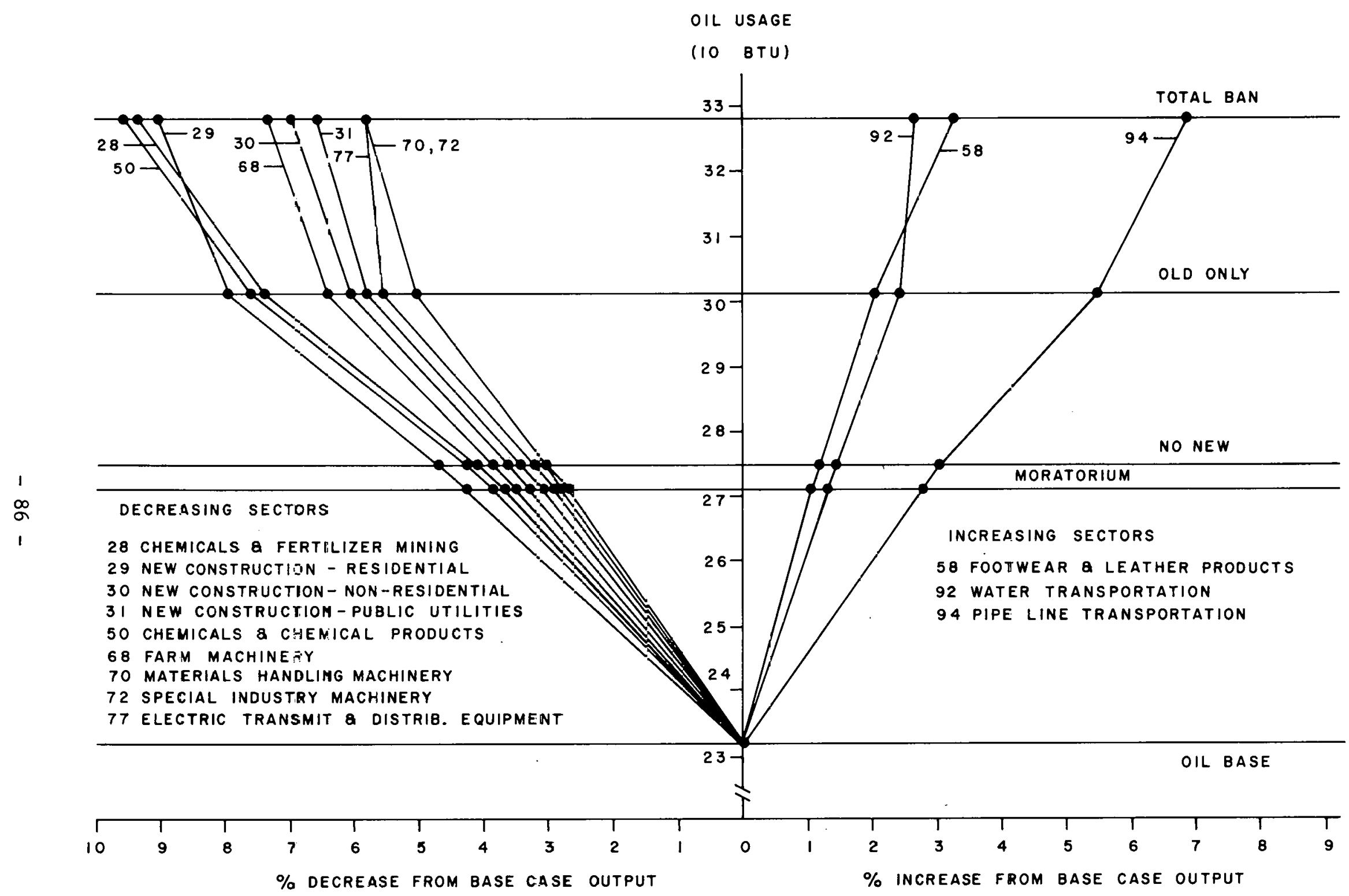

ALL NON-ENERGY OUTPUTS ARE MEASURED IN CONSTANT 1967 DOLLARS.

Figure VIII.4. Percent change in 1985

base case amounts of non-energy outputs

with imported oil response to nuclear

policies. 


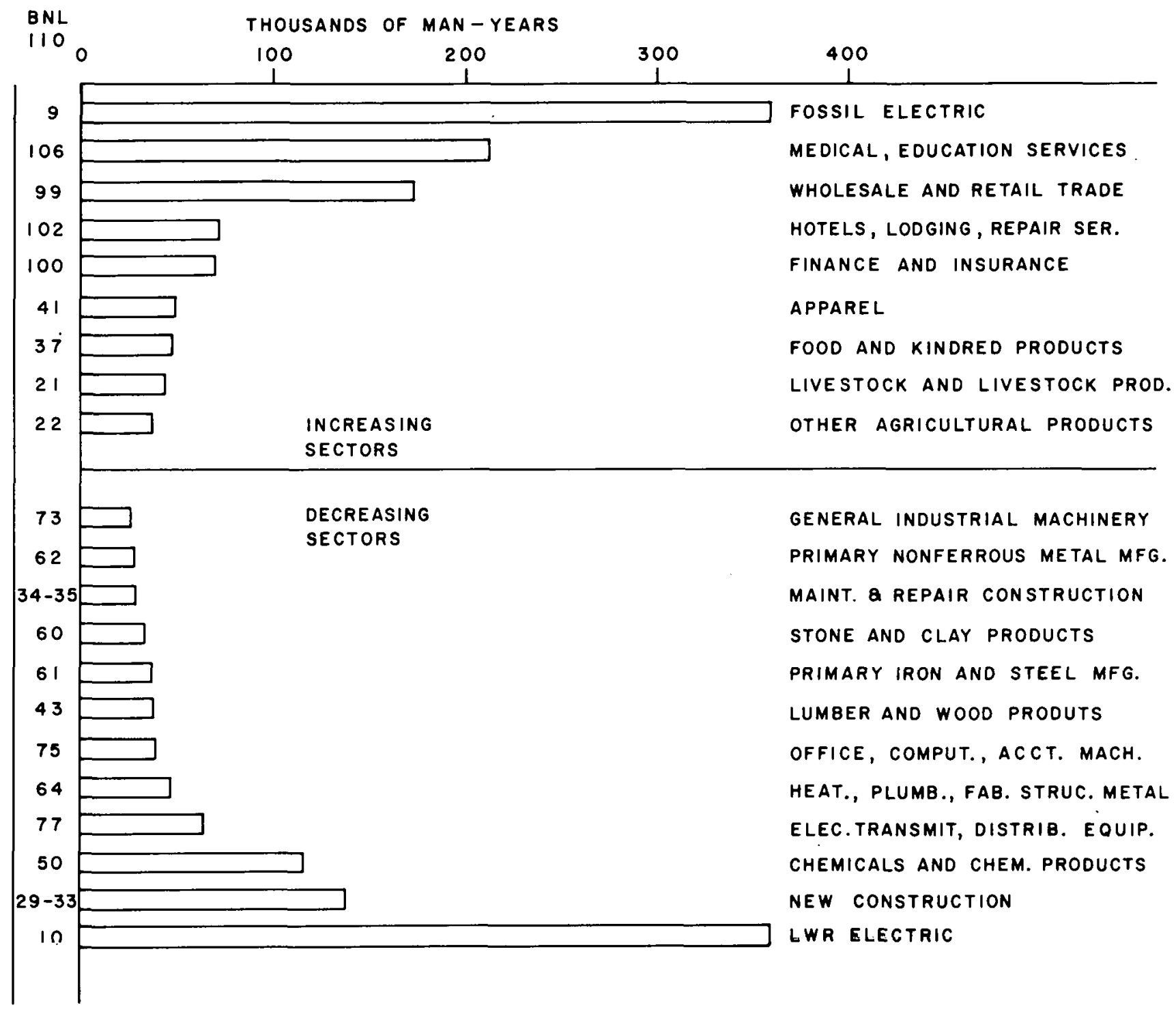

Figure VIII.5. Change in 1985 base case employment in selected industrtes w1th imported oil response to total ban nuclear policy. 
already discussed. Approximately 38 of the aggregate labor force would have to be reallocated between sectors to accomodate the Total Ban policy case. Aggregate employment which would be required to produce the Base Case GNP increases slightly, as, on balance, labor-intensive consumption-oriented industries expand at the expense of capital intensive investment-oriented industries.

All these changes were estimated under the assumption that the price of imported oil would equal $\$ 9$ per barrel (in constant $1974 \$$ ) in 1985 for all oil imported. Should the price be higher, all these changes would be larger. Conservation Response Case

In this response case, the energy product cuellicients and final demands were reduced so as to offset any decline in GNP resulting from declines in nuclear electric capacity. First, the nuclear capacities were decreased by amounts corresponding to the nuclear policies described in Chapter VI. Then, keeping all the other IO-LP'exogenous parameters at Base Case 1985 values, all the A and $A_{F I}$ energy product coefficients and the $Y_{P}$ energy product final demands were multiplied by a scaler $\delta$, the magnitude of which was changed until a feasible solution was obtained for each nuclear amount. For each nuclear policy, a corresponding value of $\delta$ was estimated, and compared with the implicit value of $\delta=1$ for the Base Case.

The percentage change in $\delta$, along with percentage changes in selected energy and economic variables, are listed in Table VIII.b for each nuclear policy. For the "No New" policy case the assoclated reduction in nuclear capacity resulted in a $14.7 \%$ decrease in electricity generating capacity and a 4.3\% decline in total primary energy inputs. Thus an $8.0 \%$ reduction in all energy demands would be required to keep GNP (net of energy) constant at the Base Case level. Inter-fuel substitution of gas and oil for electricity 


\section{Table VIII.5}

Conservation Response Case Model Results

(All Changes Relative to Estimated 1985 Base Case Amounts)

\begin{abstract}
Reduction in Energy Demands Required to

Keep GNP Constant
\end{abstract}

Nuclear Policy

Moratorium

No New

old only

Total Ban
$6.5 \%$

8.08

$14.4 \%$

17.08

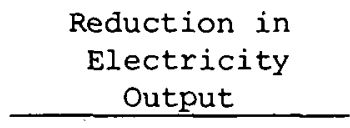

$9.5 \%$

$11.7 \%$

$17.5 \%$

30.18
Reduction in

Electricity Capacity

12.38

$14.7 \%$

21.28

$34.8 \%$
Increase in Personal Consumption Expenditures

Moratorium

No New

old only

Total Ban
1.48

1.68

2.38

3.38
Reduction in

Gross Investment

$6.4 \%$

$7.5 \%$

$10.8 \%$

15.48

Source: Model results. 
in heating demands would limit the required conservation response to an amount less than the $14.7 \%$ decline in electricity capacity. However inter-fuel substitution would not be sufficient to limit the required demand reduction to the $4.3 \%$ decline in aggregate energy input. This is due to the fact that for air conditioning, lighting, and other household and industrial appliance uses of energy, electricity is the only feasible energy power source in the time frame considered.

In interpreting these results, several considerations should be kept in mind. First, the question as to how much these efficiencies (and/or consumption amounts) would actually change with a shortage in electricity is not considered here. To answer this question, some assumptions have to be made concerning the reaction of efficiencies and demands to price changes and/or to shortage-induced public policy changes. Most changes in electrical efficiencies would involve replacing the capital stock, rather than retrofitting the existing capital stock with energy saving features. Thus most technologyoriented conservation is a long run proposition. Some one-shot increases in efficiencies may be possible, but many of these improvements may have already. been adopted following the recent large energy price increases. 
A second assumption must also be kept in mind when interpreting these results. These estimated efficiency increases were assumed to come "free." That is, no allowance was made for any increase in capital, labor and material costs associated with increasing energy efficiencies. When both the efficiencies and the nuclear capacities were changed simultaneously, aggregate investment expenditures drop up to $15.4 \%$ in the Total Ban case as a result of decreased nuclear investment. To the extent that the increases in efficiencies could be produced at a cost less than the declines in nuclear related investment, the level of personal consumption would still increase over the Base Case aggregate consumption levels.

Simultaneous nuclear decreases and energy efficiency increases would have differential impacts on sectorial output and employment requirements. Consumer oriented sector output would increase at the expense of investment oriented sectors. Decline in electricity and chemical outputs and in employment would be particularly large.

Comparison and Analysis of 1976 to 1985 Response Cases

The estimated relationship between GNP reductions and associated nuclear cutbacks are shown in Figure VIII. 6 for both the coal and imported oil response cases. In both response cases, substitution of small amounts of oil and gas for electricity limits the economic costs of small declines in nuclear capacity. However, since the possibility of substituting oil and gas for electricity is limited to the provision of a relatively small amount of space and water heating requirements, large declines in nuclear capacity necessitate correspondingly greater amounts of oil or coal electric capacity with correspondingly greater economic costs. Several other factors, not explicitly considered in the modeling portion of this analysis, would further increase the non-linearity 


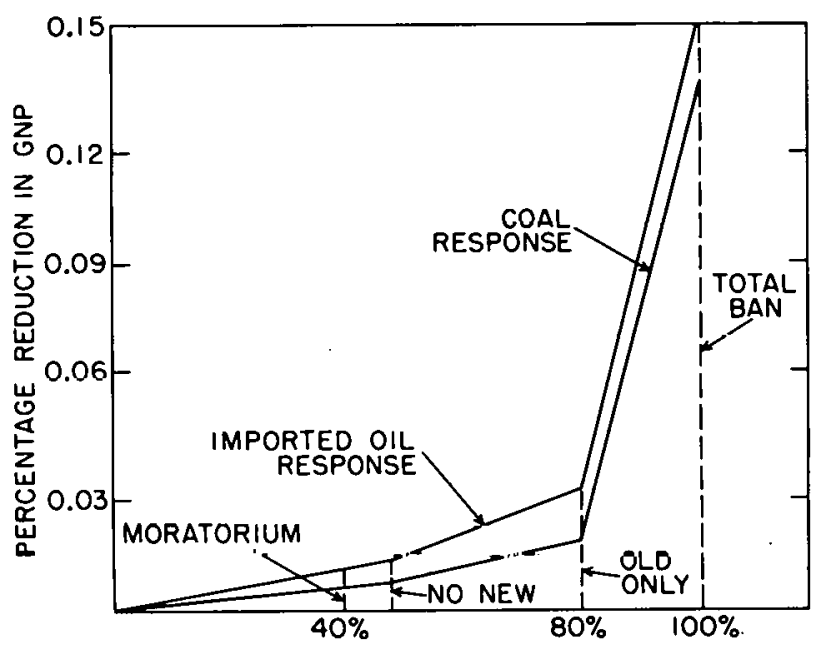

SOURCE: MODEL RESULTS

Figure VIII.6. Percentage reduction in 1985 GNP for alternative nuclear policies and supply responses. 
between the amount of the nuclear cutback and the resulting GNP reduction estimated for each supply alternative considered. The most important is the waste of nuclear plants currently in place in the Total Ban policy. Also some increase in average operating rates of existing capacity could be achieved by delaying maintenance and by adopting incentive mechanisms to smooth out the time pattern of demand for electricity. These actions would further limit the economic costs of small decreases in nuclear capacity, but would have less than proportionate impact for large decreases.

The relation between nuclear cutbacks and GNP reductions for both the coal and imported oil responses was estimated using estimated 1985 national average costs for coal, imported oil and nuclear inputs. However, the cost and availability of imported oil and particularly of coal vary considerably by region. Since in the absence of any nuclear moratoria policies, nuclear plants will tend to be installed in regions where the cost advantage of nuclear plants over oil or coal burning plants exceeds national average cost differentials, the costs of switching from nuclear to coal or oil plants in these regions would exceed the national average costs. Thus the GNP decreases associated with the imported oil and the coal response cases would, in fact, be greater than estimated.

Likewise to the extent that increases in the national average prices of coal and imported oil are required to bring forth greater supply, the economic costs in the form of GNP reductions would be greater than estimated here. However, even if the GNP reductions estimated by the model are doubled, the largest GNP reduction would equal only . .21 (for the imported oil response to a Total Ban nuclear policy). Also, any conservation response in combination with oil or coal responses would reduce GNP impacts of nuclear policies. Since nuclear 
reactors are extremely capital intensive, foregoing nuclear reactors would free considerable amounts of resources for potential reallocation to energy conservation activities.

In summary, as long as some combination of the imported oil, coal, and conservation responses can be achieved by 1985, the impact of the nuclear cutback and the associated response on GNP will be small. However, other public policy variables besides GNP would be adversely affected by nuclear cutbacks. If imported oil is used as a replacement for nuclear electricity inputs, oil imports will increase up to 9.9 quads (10 1.5 BTU's) in the Total Ban case, while if coal is used as a replacement, greater amounts of coal-related environmental damages, such as increased amounts of sulfur oxide and particulate increases, would result.

A third supply alternative, not explicitly considered in this analysis, is that utilities add base loaded oil burning gas turbine plants as replacements for planned nuclear plants. The lead time required for the installation of gas turbines currently is considerably less than those for either coal or oil steam plants. However gas turbines require 40-50\% greater amounts of oil than either coal or oil steam electric capacity to generate equivalent amounts of electricity. If just this supply alternative was pursued, oil imports would increase by approximately 14 quads in the Total Ban policy case.

Analys is of 1985 Curtailment Case

In addition to analyses allowing for compensating increases in oil and coal steam electric capacity, and/or decreases in energy demand, an analysis was made of what effect decreases in nuclear capacity would have on the 1985 economy assuming no increase in alternative oil or coal electric capacities and no voluntary decreases in amounts of energy demanded. This case can be inter- 
preted in two ways. First, it can represent a "sudden severe nuclear accident case" occurring in 1985, in which some or all of the existing 1985 nuclear capacity is shut down with no advance notice. Alternatively, with some adjustment, it can be interpreted as an extension of the 1976 nuclear policy analysis in which, because of shortages and bottlenecks, it is not possible to expand alternative electric capacities at required rates nor decrease demands voluntarily via increases in the efficiencies of energy utilizing devices.

The effects of this policy on GNP, consumption and investment are shown in Figure VIII.7, under the further assumption that electricity sales to consumers and producers all decrease proportionately. The indicated changes in GNP consumption and investment are all much larger than those estimated for the coal and imported oil responses. A $40 \%$ reduction in nuclear capacity would reduce GNP by $5 \%$, while a $100 \%$ reduction would reduce GNP by $30 \%$. In all probability several additional policies not considered in this analysis would reduce the magnitude of these GNP reductions. For example, utilities might increase operating rates of plants previously used for temporary peak demands by curtailing "non-essential" peak demands such as residential and commercial air conditioning. However, relative to the previous response cases analyzed, the impact of nuclear cutbacks would still be large. Implications of Results for Public Policy

1) The economic cost to the nation of replacing planned nuclear electric capacity with coal, imported oil or conservation alternatives will be small when the cost is defined solely in terms of 1985 GNP foregone, providing sutficient time exists to implement some combination of the coal, imported oil and conservation responses. 


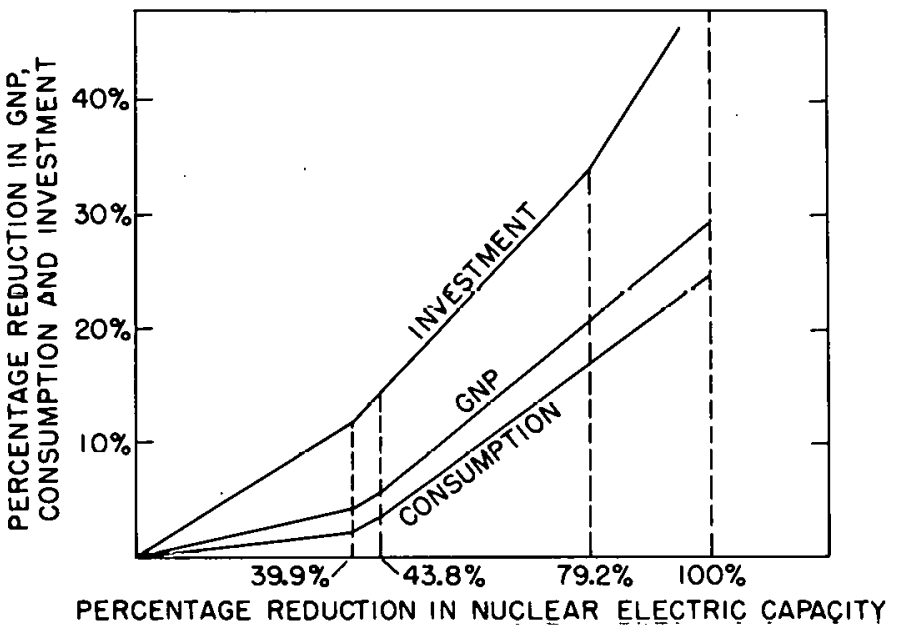

Figure VIII.7. Curtallment Case: Percent reduction in $1985 \mathrm{GNP}$, consumption and investment resulting from reductions in 1985 nuclear electric capacity. 
2) The costs of failing to provide for alternatives to nuclear power would be large, and will increase more than proportionately to the amount of nuclear shortfall which is not compensated for by some oil, coal, or conservation alternative. The 1985 GNP would decrease at most by 5 with an uncompensated $40 \%$ shortfall in nuclear capacity, but would decrease up to $30 \%$ with a $100 \%$ shortfall.

3) To keep potential future costs to a minimum, a decision as to the future of nuclear electricity should be made as quickly as possible. That is, the existing current surplus of electricity generating capacity should not be used as an excuse to delay decisions. For large nuclear cutbacks, significant reallocation of resources would be required to achieve expanded coal production and the expanded export production which would be required to permit greater importation of oil imports. In order to achieve the required reallocation, immediate planning with respect to capital decisions would be required. Even conservation alternatives would require changes in energy using capital equipment, changes which can only be implemented gradually over time.

4) Further research is needed as to which alternatives should be pursued if nuclear capacity is to be cut back or phased out completely. The alternatives to be adopted will depend upon regional, as well as national, considerations -- the important regional considerations including the regional cost of coal vs imported oil; the important national considerations including the aggregate amount of imported oil which is compatible with national security. That is, the issue of nuclear power cannot be decided in isolation, but must be considered as one piece of the whole energy policy puzzle, where the other pieces include environmental, lifestyle and national security considerations. 
1. 1976 National Energy Outlook, Federal Energy Administration, FEA-N-75/713, Government Printing Office, Washington, D.C., February 1976.

2. Armbruster, Frank et. al. Policy Analysis for Coal Development, A Report Submitted to the office of Coal Research, U.S. Department of Interior, Hudson Institute Research and Development Report No. 87, February 4, 1974.

3. Hudson, E. A. and Jorgenson, D. W. "U.S. Energy Policy and Economic Growth, 1975-2000." The Bell Journal of Economics and Management Science, Vol. 5, No. 2, Autumn 1974.

4. Behling, David et. al. "Ä 'Iwo-Level Iterative Mudel fus EsLinlaliny Inlerfuel Substitution Effects," BNL Report \#19863, Brookhaven National Laboratory, Upton, N.Y. 11773, Contained in the 1975 Summer Computer Simulation Conference Proceedings.

5. Cherniavsky, E. A. "Brookhaven Energy System Optimization Model," BNL Report \#19569, Brookhaven National Laboratory, Upton, N.Y. 11973, December 1974 .

6. Behling, D. J. and Dennehy, G. "Estimation of Final Demands and Current Input-Output Coefficients to 1985," BNL Report \#20369, Brookhaven National Laboratory, Upton, N.Y. 11973, August 1975.

7. Behling, D. J., Hudson, E. A. and Dullien, R. The Relationship of Eneryy Growth to Economic Growth Under Alternative Energy Policies, BNL Report \#50500, Brookhaven National Laboratory, Upton, N.Y. 11973, March 1976.

8. Behling, D. J. and Dullien, R. "A Combined Linear Programming and Econometric Systems Analysis of the Relation Between Energy, Growth and the Economy," BNL Report \#21281, Brookhaven National Laboratory, Upton, N.Y. 11973, Contained in the 1976 Sumer Computer Simulation Conference Proceedings.

9. Behling, D. J. "A Dynamic Systems Analysis of the Relation Between Energy and the Economy," paper presented at Comp. Con. 76, Washington, D. C., September 1976.

10. Associated Universities, Inc.; "Reference Energy Systems and Resource Data for Usc in Assessment of Energy Technologies," AF.T 8, Brookhaven National Laboratory, Upton, N.Y. 11973.

11. Almon, C., et. al., 1985: Interindustry Forecasts of the American Economy, Lexington Books, D. C. Heath and Company, 1974.

12. U.S. Department of Labor, Bureau of Labor Statistics, Tape of 134-order 1980 and 1985 Input-Output Forecasts, unpublished. 
13. U.S. Department of Commerce, Bureau of Economic Analysis, Input-Output Structure of the U.S. Economy: 1967, Government Printing Office.

14. Just, James, et. al. New Energy Technology Coefficients and Dynamic Energy Models, U.S. Energy Research and Development Administration, ERDA-3, January 1975.

15. U.S. Energy Research and Development Report, ERDA-48, "A National Plan for Energy Research, Development and Demonstration," Washington, D.C., June 1975. 
THIS PAGE

\section{WAS INTENTIONALLY \\ LEFT BLANK}


APPENDIX A

I-O Model Sectoral Alignment

and

1985 Non-Energy Final Demand Estimates 
Table A-1

Alignment of BNL 110 with Other

classification Systems
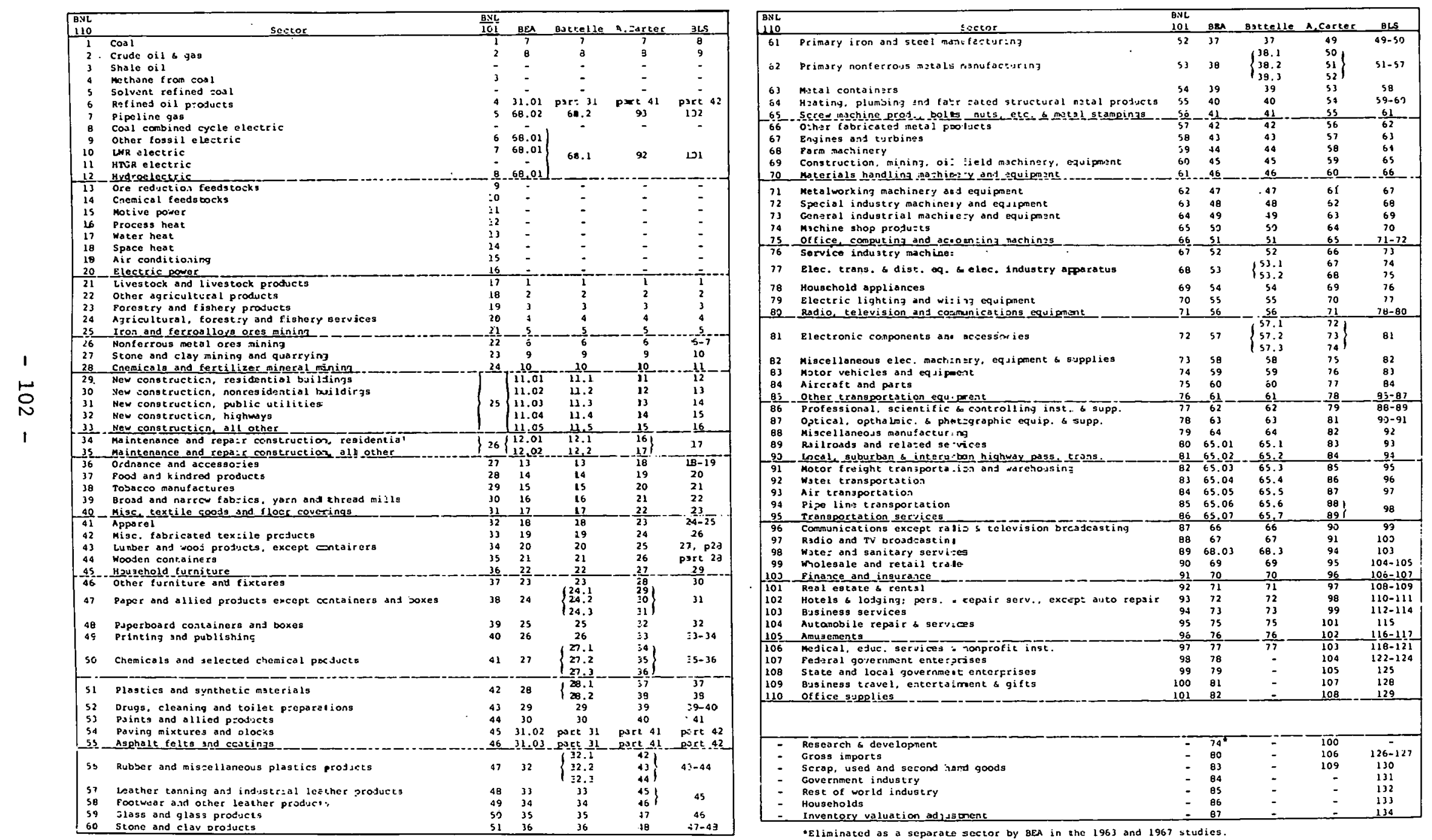
TABLE A-2

1967 AND 1985 BASE CASE NON-ENERGY FINAL DEMANDS

AND 1967-1985 ANNUAL AVERAGE GROWTH RATES BY SECTOR

BNL

\begin{tabular}{|c|c|c|c|}
\hline $\begin{array}{l}\text { 110-Order } \\
\text { Sector }\end{array}$ & $\begin{array}{l}1967 \text { Final Demand } \\
\text { (billions of } 1967 \$ \text { ) }\end{array}$ & $\begin{array}{l}1985 \text { Final Demand } \\
\text { (billions of } 1967 \$ \text { ) }\end{array}$ & $\begin{array}{r}\text { 1967-1985 Annual } \\
\text { Rate }(\% / \mathrm{yr}) \\
\end{array}$ \\
\hline 2.1 & 1.7991 & 3.8966 & 4.4 \\
\hline 22 & 6.8242 & 11.3049 & 2.8 \\
\hline 23 & -.2993 & -.1075 & -5.5 \\
\hline 24 & .1792 & .0441 & -7.5 \\
\hline 25 & -.5188 & -.6088 & .9 \\
\hline 26 & -.2078 & -.2665 & 1.4 \\
\hline 27 & -.0709 & .0578 & -- \\
\hline 28 & .0900 & -.2066 & -- \\
\hline 29 & & 45.0923 & \\
\hline 30 & & 36.7000 & \\
\hline 31 & 79.8890 & 24.6394 & 2.4 \\
\hline 32 & & 6.9012 & \\
\hline 33 & & 8.4337 & \\
\hline 34 & & .2045 & \\
\hline 35 & 5.6946 & 11.3220 & 4.0 \\
\hline 36 & 9.0000 & 6.2391 & -2.0 \\
\hline 37 & 63.3609 & 103.7071 & 2.8 \\
\hline 38 & 6.0353 & 7.6751 & 1.3 \\
\hline 39 & .5295 & 1.1820 & 4.6 \\
\hline 40 & 1.2620 & 2.4996 & 3.9 \\
\hline 41 & 16.8029 & 27.0103 & 2.7 \\
\hline 42 & 2.4579 & 4.2852 & 3.1 \\
\hline 43 & -.1617 & .0991 & -- \\
\hline 44 & .0269 & .0085 & -6.2 \\
\hline 45 & 1.1830 & 6.6764 & 2.6 \\
\hline 46 & 2.1669 & 3.6136 & 2.9 \\
\hline 47 & 1.2527 & 4.3357 & 7.1 \\
\hline 48 & .1780 & .5572 & 6.5 \\
\hline 49 & 5.7389 & 9.8982 & 3.1 \\
\hline 50 & 3.6465 & 6.8787 & 3.6 \\
\hline 51 & .6272 & 2..3].50 & 7.5 \\
\hline 52 & 8.5343 & 23.1856 & 5.7 \\
\hline 53 & .1595 & .2209 & 1.8 \\
\hline 54 & .0087 & .0142 & 2.8 \\
\hline 55 & .0181 & .0019 & -2.3 \\
\hline 56 & 3.1014 & 7.5414 & 5.1 \\
\hline 57 & -.0765 & 7.5414 & 5.1 \\
\hline 58 & 3.7034 & 3.1211 & -.9 \\
\hline 5 & .4489 & .6027 & 1.7 \\
\hline 60 & .3819 & .5677 & 2.2 \\
\hline 61 & $=.8154$ & -1.3264 & 2.7 \\
\hline 62 & -1.0440 & -.6169 & -2.9 \\
\hline
\end{tabular}


TABLE A-2 (cont.)

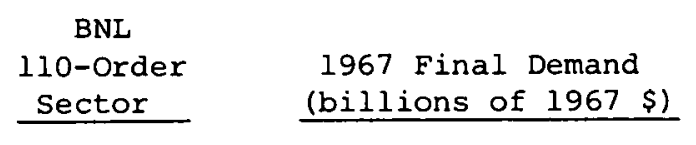

63

64

65

66

67

68

69

70

71

72

73

74

75

76

77

78

79

80

81

82

83

84

85

86

87

88

89

$9 n$

91

92

93

94

95

96

97

98

99

100

101

102

103

104

105

106

107

108

109

110 (billions of 1967 \$)

$$
\begin{aligned}
& .0928 \\
& 1.5683 \\
& .7551 \\
& 1.6919 \\
& 1.6673 \\
& \text { 3. } 5770 \\
& \text { 4. } 0255 \\
& \text { 1. } 3510 \\
& 4.0512 \\
& 3.8687 \\
& \text { 2. } 7283 \\
& .3338 \\
& 4.8290 \\
& \text { 2. } 8315 \\
& \text { 4. } 2516 \\
& 3.9441 \\
& .8937 \\
& 12.9390 \\
& \text { 1. } 2592 \\
& \text { 1. } 1741 \\
& 27.6493 \\
& 14.6217 \\
& 6.2830 \\
& \text { 3. } 0991 \\
& \text { 2. } 7022 \\
& 5.0311 \\
& 3.8319 \\
& \text { 3. } 1774 \\
& 5.7201 \\
& \text { 2. } 4549 \\
& \text { 3. } 9847 \\
& .3320 \\
& .1147 \\
& 10.0908 \\
& .0072 \\
& 1.8985 \\
& 120.8510 \\
& 25.7981 \\
& 74.4550 \\
& 16.1649 \\
& 9.2897 \\
& 8.2853 \\
& 6.0569 \\
& 45.8189 \\
& 1.8408 \\
& \text { 1. } 2329 \\
& -.3560 \\
& .4697
\end{aligned}
$$

\begin{tabular}{l}
1985 Final Demand . \\
(billions of 1967 \$) \\
\hline
\end{tabular}

.0685
2.3635
.9351
3.0275
4.0528
4.1704
7.4036
2.6463
4.1890
4.7810
4.3182
.4432

15.8243

7.3819

7.1804

8.8906

1.7718

23.6306

3.5363

2. 3119

62.8703

18.0732

15.7548

5.4202

7.0064

10.9330

6.2853

3.2604

10.4647

3.8463

8. 9480

.2051

.3634

27.3695

.1919

2.4473

237.5128

50.9625

151.5916

27.641 .7

16.0924

13.097

9. 2419

99.3119

4.8845

2. 6861

.6561

1. 3698
1967-1985 Annual Growth Rate $(\% / \mathrm{yr})$

-1.7
2.3
1.2
3.3
5.1
.9
3.4
3.8
.2
1.2
2.6
1.6
6.8
5.5
3.0
4.6
3.9
3.4
5.9
3.8
4.7
1.2
5.2
3.2
5.4
4.4
2.8
.1
3.4
2.5
4.6
-2.6
6.6
5.7
20.0
1.4
3.8
3.9
4.0
3.0
3.1
2.6
4.4
3.5
3.9


APPENDIX B

Cost Tables for Linear Proqraming Model:

- $105^{\circ}-$ 
$\mathrm{Tabl}=\mathrm{B}-\mathrm{l}$

Capital cost

:1974\$ $/ \mathrm{kw})$

\section{Central Station Eleztric}

$\underline{1985}$

Coal-Fired S.team ElEctric

Oil-Fired Stear Ele:ztric

280

Gas-Fired Stæara Ele:tric

260

Hydroeiectri:

I

ケ용

I

$\begin{array}{lc}\text { Geothermal } & -65 \\ \text { Nuclear, LWF: } & 520 \\ \text { Nuclear, HTCR } & 520 \\ \text { Nuclear, LMFBR } & 520\end{array}$

Source: Energy Tecknology Assessment Group, Brcokhaven National Laboratcry.

T.able $\mathrm{B}-2$

Capital Ccs= of Power Plants

$$
(1974 ; / k W)
$$

Devices for Electric

Generation or Storage

to Meet Peak Jemands

Coal-Fired Stean Electric, Combined Cycle

Oil-Fired Steam Electric, Combined Cycle

Oil-Fired Gas Turbine

Pumped storage

Stbstation Fuel cell

Btik Storage Ba亡tery

Tctal Energy

Sclar Decentralized,

Electric

Electrolytic Hycrogen cells Brookhaven National Laboratory 
Table $B-3$

Synthetic Fuel Plant Capital Costs in 1974 \$

For Production of $250 \times 10^{9}$ BTU/Day

$\begin{array}{lcc}\text { Process (*) } & \begin{array}{c}\text { Capital } \\ \left(10^{6} \text { Dollars }\right)\end{array} & \begin{array}{c}\text { Oper. \& Maint. } \\ \text { (c/10 }{ }^{6} \text { BTU) }\end{array} \\ \text { Hydrogen from coal (.65) } & 760 & 25 \\ \text { Syncrude from shale (.96) } & 940 & 26 \\ \text { Nat. gas from coal (.62) } & 150 & 53 \\ \text { Nat. gas from crude oil (.79) } & 1560 & 30 \\ \text { Methanol from coal (.65) } & 770 & 20 \\ \text { Syncrude from coal (.67) } & 675 & \\ \text { Low BTU gas from coal (.75) } & \end{array}$

Table B-4

Capital Cost of Electric

Transmission and Distribution

$(1974 \$ / \mathrm{kW})$

1985

Electric transmission facilities

75

Electric distribution facilities

145

Source: Energy Technology Assessment Gruup, Brookhaven National Laboratory. 
Table B-5

Raw Fuel Costs in 1974 \$

Natural Gas

Natural gas at the wellhead $\left(\xi / 1000 \mathrm{ft}^{3}\right)$

$\underline{\text { Oil }}$

Crude oil $(\$ / \mathrm{bb} 1)$

9.00

\section{$\underline{\text { Coal }}$}

Coal from underground at the mine moutr. ( $\$ /$ ton)

Coal from surface mines at the mine $(s / \tan )$

82.0

14.50

Table B-6

Synthetic Fuel Cost

$$
\text { (1974\$/10 } 6 \text { Btu) }
$$

.

\section{Nuclear*}

LWR $\left(\xi / 10^{6}\right.$ Btu $(t)$

30.0

HTGR $\left(\xi / 10^{6}\right.$ Btu(t)

30.0

LMFBR $\left(\xi / 10^{6}\right.$ Btu(t)
20.0
*This value is the cost per $10^{6}$ etu of niclear fuel input to the plant, and should be divided by the plant conversion Efficiersy to abtain f; $10.63 \mathrm{tu}(\mathrm{e})$.

Source: Energy Technology Assessnent Group, Brookhaven National Laboratory. 
Table B-7

Plant Electrical Generation Conversion Efficiencies, Percent

Central Station Electric

Oil-Fired Steam Electric

Gas-Fired Steam Electric

Hydroelectric

Geothermal

Nuclear, LWR

Nuclear, HTGR

Nuclear, LMFBR

Peaking and Storage Devices

Coal-Fired Steam Electric, Combined Cycle

Oil-Fired Steam Electric, Combined Cycle

Electrolytic Hydrogen Cells

Oil-Fired Gas Turbine

Pumped Storage

75

Substation Fuel Cell

Bulk Storage Battery

Total Energy

Source: Energy Technology Assessment Group, Brookhaven National Laboratory. 
Table B-8

Processed Fuel Costs in $1974 \$$

$\underline{\text { Petroleum }}$

$\underline{1970} \underline{1985}$

Gasoline at the refinery (\$/gal) $\quad 0.135 \quad 0.27$

Refinery price of No. 2 fuel oil (\$/gal)

$0.110 \quad 0.28$

Average refinery price of jet

fuel (kerosine) ( $\$ /$ gal)

$0.132 \quad 0.27$

Average refinery price of No. 6

$\begin{array}{llll}\text { fuel oil (residual oil) } & (\$ / \mathrm{bbl}) & 2.57 & 9.00\end{array}$

Source: Energy Technology Assessment Group, Brookhaven National Laboratory.

Table $\mathrm{B}-9$

Delivered Fuel costs in $1974 \$$

Petroleum

1970

1985

Gasoline at the scrvice station

less taxes $(s /$ gal)

ก. 252

0.43

Average delivered price of No. 2

fuel oil (\$/gal)

Average cost of oil to electric

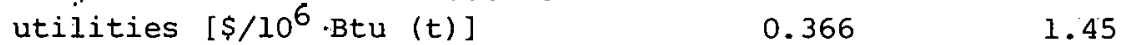

Residual oil by sulphur content in 1970* --

Average price to all utilities ( $\left.\$ / 10^{6} \mathrm{Btu}\right)$
0.58 or less
$0.6 \dot{37}$
1.60
$0.51 z$ LU $2 \hat{z} \mathrm{~S}$
0.515
1.42
$2.01 \%$ or more
0.377
1.25
Average
0.487
1.45

*1972 data corrected to 1970.

Source: Energy Technology Assessment Group, Brookhaven National Laboratory. 
Table $B-10$

Delivered Fuel Costs in 1974 \$

$\begin{array}{lll}\text { Natural Gas }\left(\$ / 10^{6} \mathrm{Btu}\right) & \underline{1970} & 1985 \\ \begin{array}{l}\text { Average cost of natural gas } \\ \text { delivered to residential }\end{array} & 1.05 & 1.75 \\ \begin{array}{l}\text { Average cost of natural gas } \\ \text { delivered to commercial }\end{array} & 0.81 & 1.47 \\ \begin{array}{l}\text { Average cost of natural gas } \\ \text { to residential and commercial }\end{array} & 0.99 & 1.62 \\ \begin{array}{l}\text { Average cost of natural gas } \\ \text { delivered to industrial }\end{array} & & 0.96 \\ \begin{array}{l}\text { Average cost of natural gas } \\ \text { delivered to all consumers }\end{array} & 0.38 & 1.17 \\ \text { Average cost of natural gas } \\ \text { to utilities }\end{array}$

Source: Energy Technology Assessment Group, Brookhaven National Laboratory. 
Table $B-11$

Fuel Transportation and Distribution Costs in $1974 \$$

Gas $\left(\$ 10^{6}\right.$ Btu $)$

Average cost of natural gas

transmission in U.S.

nistrihution rost of residential

Distribution cost to commercial

Distribution of gas to residential and commercial

Distribution cost to industrial

Distribution cost to utility

Averaqe cost of distribution to

all consumers

\section{Petroleum products ( $\$ / g a l)$}

Transportation and distribution of gasoline

Transpurtation only of gasoline

Distribution only of gasoline $\underline{1970}$

1985

$0.099 \quad 0.099$

$0.78 \quad 0.78$

0.54

0.54

0.72

0.72

0.11

0.11

nil

nil

0.37 .

0.37

Source: Energy Technology Assessment Group, Brookhaven National Tiahoratory.

$\begin{array}{ll}0.11 & 0.11 \\ 0.02 & 0.02 \\ 0.09 & 0.09\end{array}$


Table B-12

Fuel Transportation and Distribution Costs in 1974 \$

$\begin{array}{lll}\text { Petroleum Products (\$/gal) (cont'd) } & \underline{1970} & \underline{1985} \\ \begin{array}{l}\text { Transportation and distribution of } \\ \text { No. 2 fuel oil }\end{array} & 0.075 & 0.075 \\ \begin{array}{l}\text { Transportation only of Nos. } 2 \& 6 \\ \quad \text { fuel oil, and jet fuel }\end{array} & 0.02 & 0.02 \\ \text { Distribution only of No. 2 fuel oil } & 0.055 & 0.055 \\ & & \\ \text { Coal (\$/10 }{ }^{6} \text { Btu) } & & 0.068 \\ \text { Integral train } & 0.068 & 0.12 \\ \text { Slurry pipeline } & 0.12 & 0.13 \\ \text { Shuttle train } & 0.13 & \end{array}$

Source: Energy Technology Assessment Group, Brookhaven National Laboratory. 
Table B-13

Operation and Maintenance Costs in 1974 \$

Central Station Electric

Gas \& Oil-fueled steam electric

$\left[\$ / 10^{6}\right.$ Btu (e)]

Coal-fueled steam electric

$\left[\$ / 10^{6} \mathrm{Btu}(\mathrm{e})\right]$

Nuclear-fueled steam electric

$\left[\$ / 10^{6}\right.$ Btu (e)]

\section{Dispersed Generation}

Total energy (mills/kWh)

Hydroelectric (mills/kWh)

Turbine (mills/kWh)

Geothermal $\left[\$ / 10^{6}\right.$ Btu (e)]

Coal combined cycle (mills/kWh)

oil combined cycle (mills $/ \mathrm{kWh}$ ) $\underline{1970}$

1985

0.25

0.25

0.50

0.50

0.37

0.37
2.5

2.5

0.57

3.5

0.50

$2.2^{(7)}$

1. $6^{(7)}$
0.57

3.5

0,50

2.2

1.6

Source: Energy Technology Assessment Group, Brookhaven National Laboratory. 